\title{
The Tabulae eclypsium by Giovanni Bianchini
}

by

José Chabás

Universitat Pompeu Fabra

jose.chabas@upf.edu

and

Bernard R. Goldstein

University of Pittsburgh

brg@pitt.edu 


\section{Abstract}

The Tabulae eclypsium by Giovanni Bianchini (d. after 1469) was part of a larger work, the Flores Almagesti, on mathematical astronomy. In his work on eclipses, which hitherto has not been studied in depth, Bianchini compiled new tables, strictly adhering to Ptolemy's procedures, and explained their use by means of worked examples to facilitate the task of computers. Bianchini's works were influential among his contemporaries, especially Peurbach and his student Regiomontanus, with whom Bianchini corresponded. For a variety of reasons, Regiomontanus' works have eclipsed Bianchini's. In this article, we present one of Bianchini's major works, with the aim of restoring a more balanced perspective on 15th-century mathematical astronomy in Europe.

About the Authors

JosÉ CHABÁs is professor emeritus at the Universitat Pompeu Fabra (Barcelona, Spain) and has been working on the history of late medieval and early modern astronomy. His latest book, Computational Astronomy in the Middle Ages: Sets of Astronomical Tables in Latin (Madrid: CSIC, 2019), surveys the major astronomical tables in that period. He contributed to this article within the framework of the European Research Council project ALFA Shaping a European Scientific Scene: Alfonsine Astronomy (grant agreement 723085), a project in which he remains actively engaged.

BERNARD R. GOLDSTEIN, university professor emeritus in the Dietrich School of Arts and Sciences of the University of Pittsburgh, has been collaborating with José Chabás for close to three decades. Among their joint publications are The Alfonsine Tables of Toledo (Archimedes: New Studies in the History and Philosophy of Science and Technology 8. Dordrecht: Kluwer, 2003); Essays on Medieval Computational Astronomy (Leiden: Brill, 2015); and "The Medieval Moon in a Matrix: Double Argument Tables for Lunar Motion”, Archive for History of Exact Sciences 73 (2019) 335-359. 


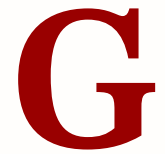

iovanni Bianchini (d. after 1469) worked in Ferrara as general administrator of the estate of the powerful family d'Este, first for Nicolò (d. 1441), Signore of Ferrara, Modena, Parma, and Reggio, then for Leonello (d. 1450), and finally for Borso (d. 1471). While not much is known about his life and his professional activities, Bianchini's scientific work, which focused on mathematics and astronomy, has been the subject of research in recent years. ${ }^{1}$ A survey of his works on astronomy and trigonometry has recently appeared [Chabás 2019, 337-364]. Bianchini also composed a text on an instrument to determine the altitude of celestial bodies [Garuti 1992]. However, his main work on astronomy is a long text entitled Flores Almagesti, which deals with all major problems of astronomy and includes extensive discussions on arithmetic and algebra. ${ }^{2}$ Of particular interest to us are several sets of astronomical and trigonometrical tables that Bianchini compiled.

The Flores Almagesti, Bianchini's most ambitious work, was composed over a long period, from 1440 to at least 1456 . The text has not yet been edited and its contents have not been thoroughly examined. ${ }^{3}$ His most extensive set of tables, called Tabulae astronomiae, concerns planetary motion and was completed in 1442. Ten years later, he presented this set to the Holy Roman emperor Frederick III (1415-1493) during his visit to Ferrara. It is Bianchini's only work to have been published (first edition: Venice 1495) and has recently been studied in Chabás and Goldstein 2009. In addition to a series of precise trigonometric tables with a norm of 60,000 , Bianchini compiled three other sets of tables. The Tabulae magistrales is an independent set of eight auxiliary tables addressing problems in spherical astronomy,

${ }^{1}$ For Bianchini's life and works, see Federici Vescovini 1968: cf. Boffito 1907-1908, and Magrini 1917.

2 For Bianchini’s mathematical activity, see Rosińska 1984, 1996, 1997, 1998, and 2006.

3 A list of the rubrics of the Flores Almagesti, based on Paris, BnF, MS lat. 10253, was published in Thorndike 1950, 176-180. See also Thorndike 1953, 5-17. These two articles provide relevant information on Bianchini's works and the manuscripts containing them. 
which has been analyzed recently in Chabás 2016. Among these tables is an innovative decimal table for the tangent function. The study of the Tabulae primi mobilis, a set of tables focusing on problems related to spherical astronomy accompanied by a text, is now underway and preliminary results are already available [see Van Brummelen 2018 and 2021]. The third set, the Tabulae eclypsium, consisting of a text and various tables, is the subject of the present paper.

\section{Texts and tables}

The text that accompanies the Tabulae eclypsium consists of 39 chapters under the title "Canones tabularum de eclypsibus luminarium de Blanchini editarum". The contents of this text have not been addressed in the modern scholarly literature. The canons are preceded by a Prohemium beginning "In libro Florum Almagesti per Ioannem Blanchinum demonstrati est componere tabulas necessarias". The titles of the chapters, or their incipits when there is no title, are listed in the Appendix [p. 38 below]. The tables associated with the text are sometimes found independently, often together with other tables compiled by Bianchini, not necessarily on eclipses.

We examined the following manuscripts:

- Bologna, Biblioteca Comunale, MS 1601, 17v-3or (canons), 71v-73V (tables) [henceforth, BC];

- Cracow, Biblioteka Jagiellońska, MS 556, 25r-34V (canons), 40r-41V (tables), dated 1469 [henceforth, $\mathrm{C} 1$ ];

- Oxford, Bodleian Library, MS Can. Misc. 517, 99v-111r (canons), 157r-159v (tables);

- Paris, Bibliothèque nationale de France, MS lat. 7270, 167r-181r (canons), 233r-235V (tables), dated 1461[henceforth, P1];

- Paris, Bibliothèque nationale de France, MS lat. 7271, 169r-18or (canons), 237r-238r, 240r-v (tables);

- Paris, Bibliothèque nationale de France, MS lat. 7286, 82r-92r (canons), 136r, 137r-138v (tables) [henceforth, P2];

- Paris, Bibliothèque nationale de France, MS lat. 10265, 84r-85v, 87r, 222r (tables) [henceforth $\mathrm{P}_{3}$ ];

- Paris, Bibliothèque nationale de France, MS lat. 10267, 81r-106v (canons), dated 1468 [henceforth, $\mathrm{P} 4$ ];

- Vatican, Biblioteca Apostolica, MS Vat. lat. 2228, 1r-16r (canons), dated 1470 [henceforth, Va];

- Vatican, Biblioteca Apostolica, MS Vat. lat. 3538, 38r-41r (tables);

- Venice, Museo Civico Correr, MS Cicogna 3748, 153r-164r (canons). 
For the canons, we have used MS P1 as a guide, since it is the earliest manuscript known to contain this work (dated 1461). But for the tables, we have mainly used MS C1.

By far, the predecessor most cited in the canons is Ptolemy, for whom Bianchini had great admiration, specifically for his Almagest. Other ancient scholars mentioned are Euclid and Hipparchus. Bianchini also refers to some later scholars, notably al-Battānī (d. 929) and Ioannes Anglicus (13th century), as well as to several astronomical works, such as the Toledan Tables and the Alfonsine Tables.

The text of the Tabulae eclypsium contains many references to Bianchini's Flores Almagesti. As will be explained below, a few chapters of the canons to the Tabulae eclypsium were taken verbatim from the Flores Almagesti, which is extant in a small number of manuscripts:

- Bologna, Biblioteca Universitaria, MS 293, 3r-109v [henceforth BU];

- Cracow, Biblioteka Jagiellońska, MS 558, 1r-10or [henceforth C2];

- Paris, Bibliothèque nationale de France, MS lat. 10253, 6r-138v (dated 1481);

- Perugia, Biblioteca Comunale Augusta, MS 1004, 1r-77r;

- Vatican, Biblioteca Apostolica, MS Vat. lat. 2228, 16v-51v, 78r-120r (dated 1470).

In addition to the above manuscripts, the Flores Almagesti is partially preserved in Cracow, Biblioteka Jagiellońska, MS 601, 62v-68v, and Vatican, Biblioteca Apostolica, MS Reg. lat. 1904, 1r-56r.

The Flores Almagesti consists of eight treatises, divided into books and then into chapters. The text begins

Tractatus primus de arismetica per Iohannem de Blanchinis. Liber primus, Incipit prohemium. Aritmethrica dico quod determinator per numeros, and ends "cum quibus perficientur opus nutu Dei gloriosi”.

The various copyists did not agree on the number of treatises in the Flores Almagesti, and it is often the case that the titles and the numbering of the chapters have been omitted. This has generated many errors in cataloging this work. Fortunately, the sequence of chapters is almost the same in all manuscripts. Comparison of the different copies indicates the following structure:

- treatise 1 on arithmetic;

- treatise 2 on algebra;

- treatises 3 and 4 on trigonometry;

- treatise 5 on spherical astronomy; 
- treatises 6, 7, and 8 on astronomy.

The Flores Almagesti and the Tabulae eclypsium are closely related, and one part of the Flores (specifically, the closing chapters of treatise 7) was "recycled" as the first six chapters of the canons to the Tabulae eclypsium. ${ }^{4}$ In MS C2, a manuscript of Italian provenance with annotations ascribed to Regiomontanus, the Flores ends on $\mathrm{f}$. 10or. In the remainder of the manuscript there is a copy of other chapters (7-21 and 24-38) of the Tabulae eclypsium, as well as short canons on the lunar node and the color of eclipses, up to f. 116r. The same arrangement is found in MS BU, where the Flores ends on f. 109v, and chapters 7-21 and 24-38 of the Tabulae eclypsium were appended, together with the short canons on the lunar node and the color of eclipses. The copyist considered these additions as treatises 9 and 10. The additions in MSS $\mathrm{C}_{2}$ and $\mathrm{BU}$ point to a strong relationship between these two manuscripts.

The date of the Flores Almagesti is uncertain, but it is known that the text was still being written in 1456 , as stated in treatise 6 , chapter $1 ; 5$ and during the period that it took Bianchini to complete it, he wrote other texts and compiled other tables. Considered as a whole, the Flores Almagesti seems to be an attempt by Bianchini to update Ptolemy's Almagest.

2. Table for the angle between the meridian and the ecliptic

In the computation of eclipses, lunar parallax plays a critical role, and this is the first topic that Bianchini addresses in his Tabulae eclypsium, thus following Ptolemy closely.

In Almagest 5.18, Ptolemy presents a table in nine columns to compute parallax in altitude, from which the components in longitude and latitude can be determined [Toomer 1984, 265]. For that purpose, the angle between the great circle passing through the zenith (i.e., a vertical circle) and the lunar orb is needed. In Alm.5.19, Ptolemy explains that it is sufficient to approximate this angle by taking the angle between a vertical circle and the ecliptic; and in Alm.2.13, he provides tables for the angles between the ecliptic and the verticals for the seven climates, each zodiacal sign, and

4 The text of the relevant chapter in Flores Almagesti is the same as that opening the Tabulae eclypsium but for slight differences in the incipits: "Hucusque demonstrandum est componere tabulas necessarias" (Flores Almagesti) and "In libro Florum Almagesti per Ioannem Blanchinum demostratum est componere tabulas necessarias" (Tabulae eclypsium).

5 See, e.g., MS C2, 49r-v, where 1456 is referred to as "the present year". 
each hour of the day [Toomer 1984, 267, 122-130; Neugebauer 1975, 47-52]. We note that for each zodiacal sign the values for noon, that is, the angles between the ecliptic and the local meridian, are the same in all climates, and are thus valid for all geographical latitudes. Hence, only one entry is given for each zodiacal sign. The situation is illustrated in Figure 1, where $\mathrm{V}$ is the vernal point and the Moon is at $M$.

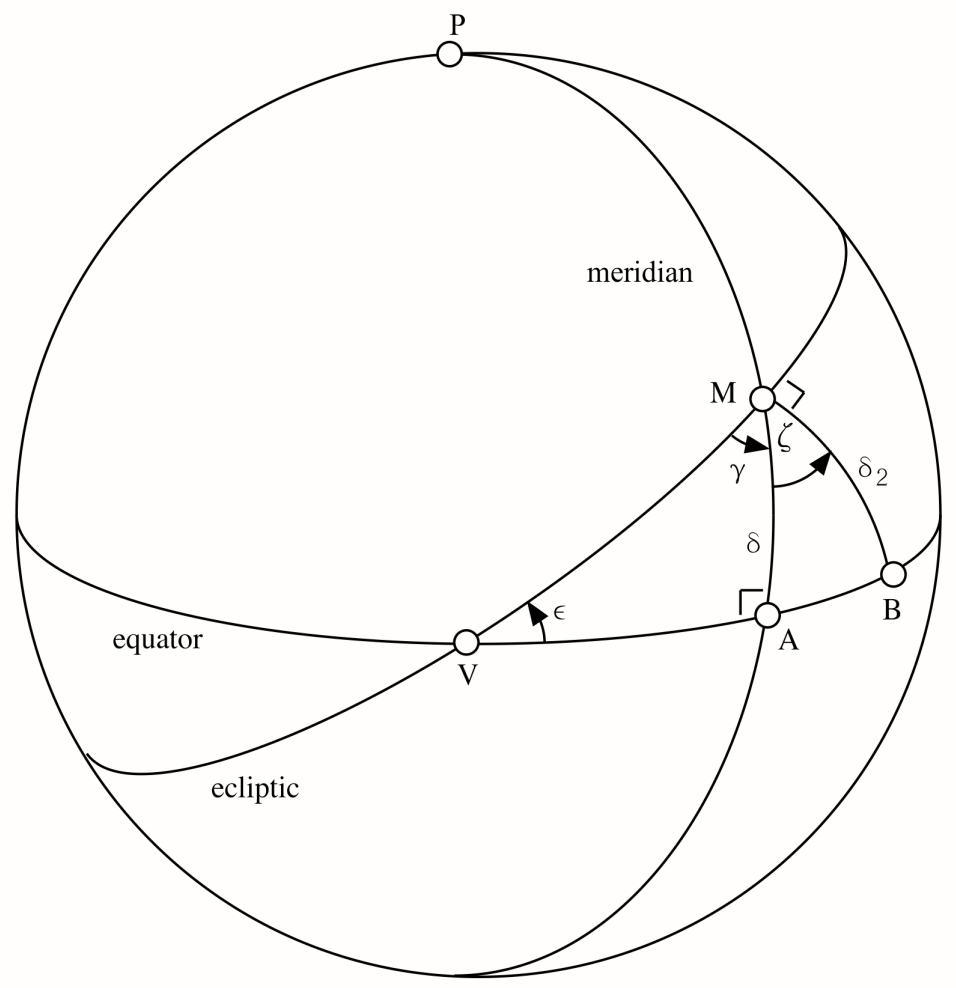

Figure 1. The angle between the ecliptic and the meridian

The first table in Bianchini's set is entitled "Tabula angulorum ex meridiano et orbe signorum in omni regione", and it is indeed a table listing the values of the eastern angles between the local meridian and the ecliptic at noon. The title correctly indicates that the table is valid for all places on Earth.

There are two major differences between Ptolemy's and Bianchini's tables. First, Bianchini gives 30 entries for each zodiacal sign at noon whereas Ptolemy only lists one-for the beginning of the sign. Second, Bianchini 
uses a value of $23 ; 33,30^{\circ}$ for the obliquity of the ecliptic, whereas Ptolemy uses $23 ; 51,20^{\circ}$.

The argument in Bianchini's table ranges from $0^{\circ}$ to $360^{\circ}$ at intervals of $1^{\circ}$, and it is presented in 12 columns, one for each zodiacal sign, beginning in Aries, in contrast to Ptolemy's tables, which begin in Cancer. The first entry in the table, for Ari $0^{\circ}$, is $66 ; 26^{\circ}$ and the entry for $\mathrm{Lib}^{\circ}$ is $113 ; 33^{\circ}$. However, in three copies, MSS $\mathrm{C}_{1}, \mathrm{P}_{2}$, and $\mathrm{BnF} 7271$, the two entries are given as $66 ; 261 / 2^{\circ}\left(=90^{\circ}-23 ; 33,30^{\circ}\right)$ and $113 ; 33^{1 / 2^{\circ}}\left(=90^{\circ}+23 ; 33,30^{\circ}\right)$. Although inspired in Ptolemy, this table is unprecedented in its format.

\begin{tabular}{cccccrc} 
& Ari & Tau & Gem & Cnc & Leo & Vir \\
\hline 0 & $66 ; 261 / 2$ & $69 ; 19$ & $77 ; 42$ & $90 ; 0$ & $102 ; 18$ & $110 ; 41$ \\
$\ldots$ & & & & & & \\
10 & $66 ; 48$ & $71 ; 32^{\mathrm{a}}$ & $81 ; 31$ & $94 ; 20$ & $105 ; 40$ & $112 ; 18$ \\
$\ldots$ & & & & & & \\
20 & $67 ; 42$ & $74 ; 20^{\mathrm{a}}$ & $85 ; 40^{\mathrm{a}}$ & $98 ; 29$ & $108 ; 28$ & $113 ; 12$ \\
$\ldots$ & & & & & & \\
30 & $69 ; 19$ & $77 ; 42$ & $90 ; 0$ & $102 ; 18$ & $110 ; 41$ & $113 ; 33^{1 / 2}$ \\
a & & & & &
\end{tabular}

Table 1. Angle between the meridian and the ecliptic (Excerpt of the first half of the table)

Let $e(x)$ be an entry in the table. Then the following symmetry relations hold:

$$
e(x)+e(180-x)=180^{\circ} \text { and } e(x)=e(360-x) .
$$

These symmetry relations make it easy to visualize the second half of the table (not displayed here) with its symmetrical entries, and to identify the faulty entries in the table.

We have found three such scribal or author's errors in the entries in Table 1.

(1) Tau $10^{\circ}$ has $71 ; 33^{\circ}$, but Aqr $20^{\circ}$ has $71 ; 32^{\circ}$, which corresponds to the entry $108 ; 28^{\circ}$ both for Leo $20^{\circ}$ and Sco $10^{\circ}$;

(2) Tau $20^{\circ}$ has $74 ; 26^{\circ}$, but Aqr $10^{\circ}$ has $74 ; 20^{\circ}$, which corresponds to the entry $105 ; 40^{\circ}$ both for Leo $10^{\circ}$ and Sco $20^{\circ}$;

(3) $\mathrm{Gem} 20^{\circ}$ has $85 ; 46^{\circ}$, but Cap $10^{\circ}$ has $85 ; 40^{\circ}$, which corresponds to the entry $94 ; 20^{\circ}$ both for Cnc $10^{\circ}$ and Sgr $20^{\circ}$.

We note that the corresponding entries in the second half of the table are correct. 
Surprisingly, all but two of the manuscripts examined share exactly the same three scribal errors and have no other such errors. The exceptions are MSS P2 and BC: in both, two errors (Tau $10^{\circ}$ and $\mathrm{Gem} 20^{\circ}$ ) are corrected, and a new one in Ari $20^{\circ}$ occurs $\left(67 ; 43^{\circ}\right.$ rather than $67 ; 42^{\circ}$, as found in the second half of the table in all manuscripts).

This topic is addressed by Bianchini in his Flores Almagesti, treatise 7, chapter 2, which is entitled "Quantitatem anguli ex meridiano et orbe signorum apud punctum quemlibet per declinationem notam invenire" [MS BU, 8ov$81 v]$. Bianchini explains Ptolemy's method for finding the angle between the meridian and the ecliptic [cf. Neugebauer 1975, 47-48]. He illustrates this method with a figure, consisting of four great circles [see Figure 2, p. 10 below]. The meridian and the equator are so labeled in the original figure. The ecliptic passes through $b, r\left(\operatorname{Libra} 0^{\circ}\right)$, and $t$. The fourth circle is drawn so that its pole is $b$ and passes through $c$ (the East point). Although not specified by Bianchini, this situation defines a spherical Menelaus configuration where $h$ is the vertex, $h c$ and $h b$ are the external arcs, and $a c$ and $b t$ are the internal arcs. On the external arc $h c$, the unknown, $\gamma-90^{\circ}$, is arc $c t$ and $h c=90^{\circ}$. On the external arc $h b$, the lunar declination, $\delta(M)$ is arc $b a$, whereas arc $a h=90^{\circ}-\delta(M)$. On the internal arc $b t$, we have $b r=180^{\circ}-\lambda(M)$ and $r t=\lambda(M)-90^{\circ}$.

In general, the Menelaus configuration in Figure 2, using sines rather than chords, may be written as

$$
\sin c t=\frac{\sin b a}{\sin a h} \cdot \frac{\sin r t}{\sin b r} \cdot \sin 90^{\circ}
$$

that is, as

$$
\sin \left(\gamma-90^{\circ}\right)=\frac{\sin \delta(M)}{\sin \left(90^{\circ}-\delta(M)\right)} \cdot \frac{\sin \left(\lambda(M)-90^{\circ}\right)}{\sin \left(180^{\circ}-\lambda(M)\right)} \cdot \sin 90^{\circ} .
$$

Bianchini considers only one case, where the Moon is at $b$, the beginning of Virgo $\left(\lambda=150^{\circ}\right)$. On the external arc which lies on the meridian, the declination $b a$ is correctly given as $\delta=11 ; 32^{\circ}$, and $a h$ is its complement in $90^{\circ}$. On the internal arc on the ecliptic, $b r$ is $30^{\circ}$ and $r t$ is its complement in $90^{\circ}$. On the external arc through $h, c$, and $k$, the arc $h c$ is $90^{\circ}$, and the unknown is arc $c t$.

For this special case and using sines normed to 60,000, Bianchini computes:

$$
\sin \left(\gamma-90^{\circ}\right)=\frac{\sin 11 ; 32^{\circ} \cdot \sin 60^{\circ} \cdot \sin 90^{\circ}}{\sin \left(90^{\circ}-11 ; 32^{\circ}\right) \cdot \sin 30^{\circ}}=21,206
$$

In Bianchini's sine table, 21,206 is indeed the sine of $20 ; 42^{\circ}$. Therefore, the angle between the meridian and the ecliptic is $90^{\circ}+20 ; 42^{\circ}=110 ; 42^{\circ}$, which corresponds almost exactly to the entry for Vir $0^{\circ}$ in Table 1 [p. 8 above] 


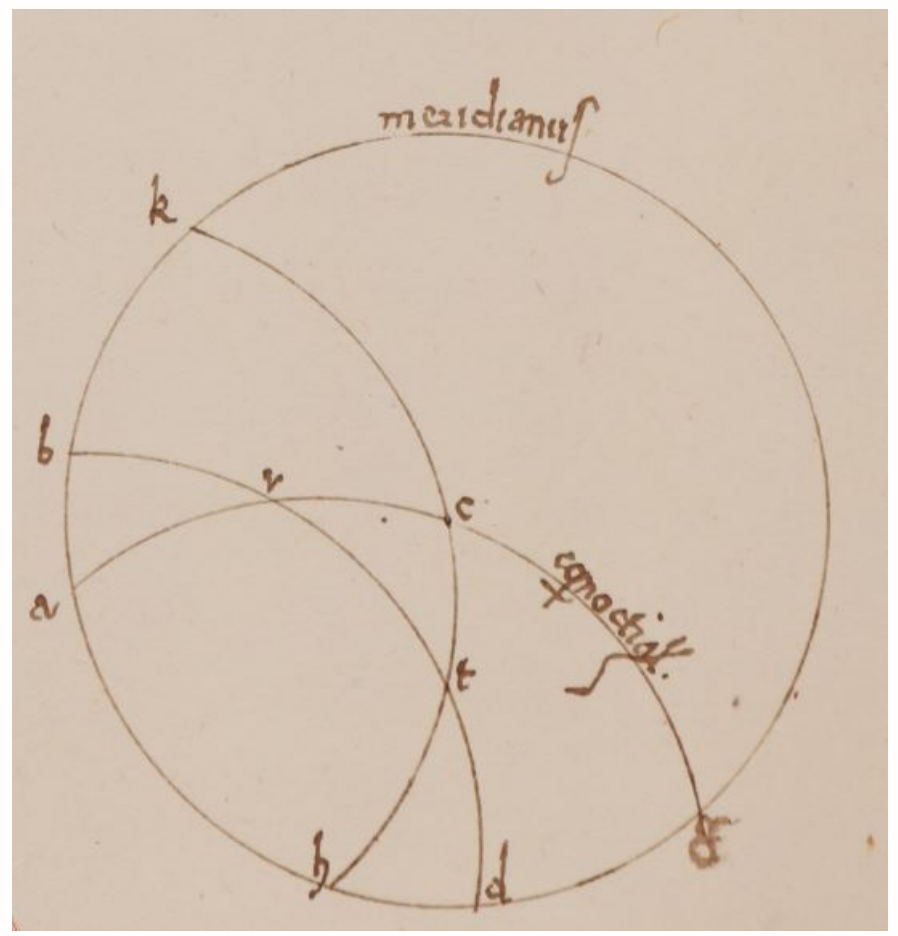

Figure 2. Bianchini's drawing for the angle between the ecliptic and the meridian [MS BU, 8ov]

$\left(110 ; 41^{\circ}\right)$. This value is consistent with the symmetrical values for Sco $0^{\circ}$ $\left(110 ; 41^{\circ}\right)$, Tau $0^{\circ}$, and $\operatorname{Psc} 0^{\circ}\left(69 ; 19^{\circ}\right)$. Bianchini adds that Ptolemy found this angle to be $111 ; 0^{\circ}$ because he used a value for the obliquity of the ecliptic $\left(23 ; 51,20^{\circ}\right)$ that is different from his $\left(23 ; 33,30^{\circ}\right)$ [cf. Alm. 2.13].

In chapter 11 of the Tabulae eclypsium, entitled "De inventione angulorum ex meridiano \& orbe signorum equaliter correspondentium in omni regione" [MS P1, 171v], Bianchini addresses the same problem and introduces another method for computing this angle, which can be expressed as:

$$
\sin \left(\gamma-90^{\circ}\right)=\frac{\tan \delta(M)}{\tan \lambda(M)} .
$$

Equation (2) is equivalent to equation (1) because $\sin \delta / \sin \left(90^{\circ}-\delta\right)$ reduces to $\tan \delta$ and $\sin \left(\lambda-90^{\circ}\right) / \sin \left(180^{\circ}-\lambda\right)$ reduces to $\tan \lambda$. The declination, $\delta$, can be derived by using the corresponding table or by means of the formula:

$$
\sin \delta=\sin \varepsilon \cdot \sin \lambda,
$$


where the obliquity of the ecliptic, $\varepsilon$, is taken to be $23 ; 33,30^{\circ}$. In this chapter, Bianchini explicitly mentions a tangent table, which he calls the fourth tabula magistralis, for computing the tangents of $\delta$ and $\lambda$ [Chabás 2016, $548,550]$. This table is mentioned several times in the Tabulae eclypsium and is used here for the first time outside spherical astronomy. In our recomputation, we have used equations (2) and (3), rather than a table for the solar declination as a function of its longitude. As shown in Table 2, the agreement between text and computation is excellent.

\begin{tabular}{rrrll}
$\lambda$ & $\delta$ & $\gamma$ & Text & \\
\hline 0 & 0 & $66 ; 26,30$ & $66 ; 26$ & or $66 ; 261 / 2$ \\
10 & $3 ; 58,47$ & $66 ; 45,41$ & $66 ; 48$ & \\
20 & $7 ; 51,25$ & $67 ; 43,10$ & $67 ; 42$ & \\
30 & $11 ; 31,40$ & $69 ; 18,47$ & $69 ; 19$ & \\
40 & $14 ; 53,12$ & $71 ; 31,48$ & $71 ; 33$ & $71 ; 32$ in the other half \\
50 & $17 ; 49,44$ & $74 ; 20,36$ & $74 ; 26$ & $74 ; 20$ in the other half \\
60 & $20 ; 15,4$ & $77 ; 42,5$ & $77 ; 42$ & \\
70 & $22 ; 3,36$ & $81 ; 31,5$ & $81 ; 31$ & \\
80 & $23 ; 10,46$ & $85 ; 40,12$ & $85 ; 46$ & $85 ; 40$ in the other half \\
90 & $23 ; 33,30$ & 90 & 90 &
\end{tabular}

Table 2. Recomputation of the entries in Table 1

(All entries are in degrees)

Bianchini could have computed the entries in this table in various other ways, since he had compiled several tables that could serve as auxiliary tables. Of particular interest here are his two different tables for declinations. One is for the usual declination, which he calls vera, measured from the equator on a great circle perpendicular to it, and the other is for what he calls novissima declinatio, a "declination" measured from the equator on a great circle perpendicular to the ecliptic, which has been called "second declination". ${ }^{6}$ These two quantities are illustrated in spherical right triangle $M A B$ in Figure 1 [p. 7 above]: $M A$ is the declination $\delta$ and $M B$ is the second declination $\delta_{2}$. The angle at $M$ between the meridian and the perpendicular to the ecliptic, that is, between MA and MB, is $\zeta=90^{\circ}-\gamma$. In this triangle,

$$
\cos \left(90^{\circ}-\gamma\right)=\frac{\tan \delta}{\tan \delta_{2}} \text {. }
$$

${ }^{6}$ See Van Brummelen 2018. Both tables are found in MS $\mathrm{P}_{3}$, 92r. 
This equation yields $\gamma$, the angle between the meridian and the ecliptic, either using its cosine or its sine, since $\cos \left(90^{\circ}-\gamma\right)=\sin \gamma$.

As mentioned above, Bianchini follows Ptolemy closely by appealing to Menelaus configurations, and updates Ptolemy's computations with new auxiliary functions, as is the case here. Table 3 displays a comparison between the results obtained by Ptolemy in Alm.2.13, based on the value for the obliquity of the ecliptic of $23 ; 51,20^{\circ}$, and those by Bianchini, based on the value of $23 ; 33,30^{\circ}$.

\begin{tabular}{rcc}
$\lambda$ & Ptolemy & Bianchini \\
\hline 0 & $66 ; 9$ & $66 ; 261 / 2$ \\
30 & $69 ; 0$ & $69 ; 19$ \\
60 & $77 ; 30$ & $77 ; 42$ \\
90 & 90 & 90 \\
120 & $102 ; 30$ & $102 ; 18$ \\
150 & $111 ; 0$ & $110 ; 41$ \\
180 & $113 ; 51$ & $113 ; 33^{1 / 2}$
\end{tabular}

Table 3. Comparison between the entries in Ptolemy and Bianchini for the angle between the ecliptic and the meridian

(All entries are in degrees)

Angle $\gamma$ is essential for determining the components of lunar parallax in longitude $\pi_{\lambda}$ and latitude $\pi_{\beta}$ when the Moon is on the meridian. But, before determining the components, it is necessary to compute the lunar parallax on a vertical circle. Bianchini does so, and the results of his computation are displayed in Tables 4 [p. 15] and 5 [p. 16].

\section{Tables for lunar parallax}

Computing lunar parallax is far from being a trivial problem. Ptolemy solved it by means of what we now call a function of three variables, which he presents in Alm. 5.18 as a table of nine columns [Toomer 1984, 265]. The entries in this table determine the lunar parallax in altitude as a function of the lunar zenith distance, anomaly, and elongation. Figure 3 [p. 13 below] shows the total parallax of the Moon, $\pi=z^{\prime}-z$, where $z^{\prime}$ is the apparent zenith distance of the Moon for an observer at $\mathrm{O}$, and $z$ is its true zenith distance from the center of the Earth. In Bianchini's words, total parallax is "differentia inter locum eius visibilem et locum verum ad regionum latitudines” [MS BU, 98r]. 


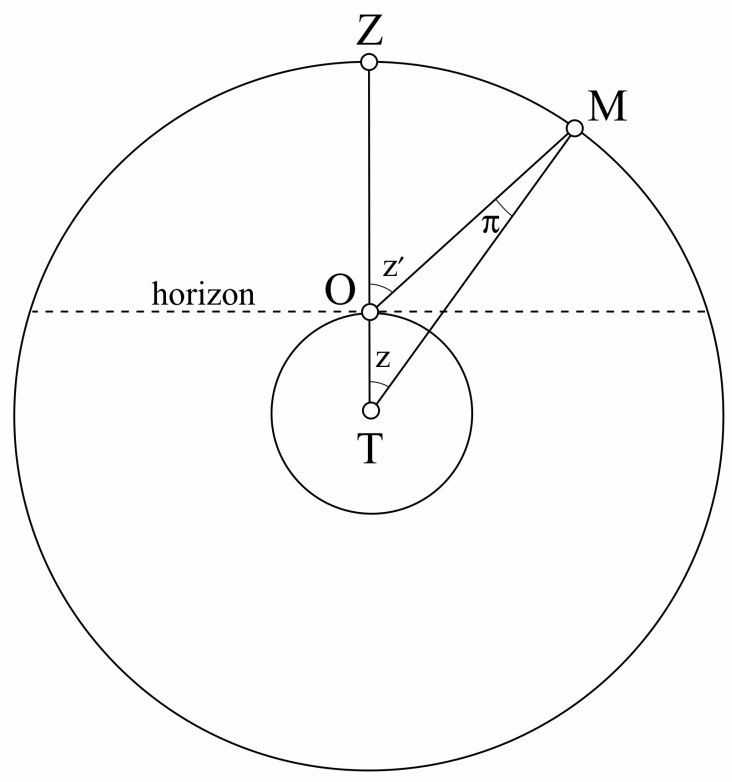

Figure 3. Lunar parallax as a function of the zenith distance $z$

Bianchini's two tables for the computation of parallax [see Tables 4 and 5] are addressed in chapter 7 of his Tabulae eclypsium, and a succinct description is given that follows the pattern established by Ptolemy. This subject was already addressed in chapters 18 and 19, at the end of treatise 7, book 2, of the Flores Almagesti, under the general title, "De modo componendi tabulas de diversitate aspectus lune" [MS BU, 98r-99v].

In contrast to Ptolemy's table in nine columns for solar and lunar parallax, Bianchini deals exclusively with lunar parallax, and thus has no column for solar parallax-we have no explanation for this. Moreover, Bianchini has two separate tables, one for the Moon at syzygy and the other for the Moon at quadrature. Despite borrowing the format already used by Ptolemy, there are a few noticeable differences. The most obvious is that in Ptolemy's table the argument ranges from $2^{\circ}$ to $90^{\circ}$ at steps of $2^{\circ}$, while in Bianchini's the argument is given for all integer values from $1^{\circ}$ to $180^{\circ}$. Thus, Bianchini extends the 45 rows in Ptolemy's table to 180 rows, thereby providing four times as many entries. This change was intended to overcome a difficulty already mentioned by Ptolemy himself in Alm. 5.19: to use his table, the three 
independent variables involved (lunar zenith distance, anomaly, and elongation between the two luminaries) must be halved. In his table, Bianchini adheres to the proper meaning of the variables: zenith distance, anomaly, and double elongation.

A second departure from Ptolemy is that the entries common to both tables do not agree. This may be surprising at first glance, given that the same model and the same parameters are used in both cases. Close examination of the entries indicates that Ptolemy computed a selection of entries in each column and applied linear interpolation, generally at intervals of $6^{\circ}$, to obtain the rest. In contrast, Bianchini seems to have computed all entries anew, without taking into account Ptolemy's entries or appealing to interpolation. Indeed, in chapter 14 of the Tabulae eclypsium, Bianchini calls attention to the fact that this is a new table: "in tabula diversitatis aspectus lune per me noviter constructa". As far as we are aware, Bianchini was the only astronomer to recompute and extend Ptolemy's table for solar and lunar parallax, which was otherwise left untouched for centuries. For example, al-Battānī limited himself to reproducing Ptolemy's table, with some variant readings [Nallino 1903-1907, 2.93-94].

In Tables 4 and 5, which display excerpts of Bianchini's tables for lunar parallax, we have used as headings the column numbers in Ptolemy's table in nine columns. In both tables, the argument $c_{1}$ is the zenith distance $\mathrm{z}$ and it is given for each integer degree from $0^{\circ}$ to $180^{\circ}$ and its complement in $360^{\circ}$.

In Table 4 [p. 15 below], the other three columns are given in minutes of arc and all apply to the Moon at syzygy. Column $\mathrm{c}_{3}$ is a function of the zenith distance and gives the lunar parallax when the Moon is at the apogee of the epicycle at syzygy. Column $\mathrm{c}_{4}$, also a function of the zenith distance, provides the increment to be applied to an entry in $c_{3}$ to obtain the parallax at perigee. For intermediary situations, a column for interpolation (called "minutes of proportion"), $c_{7}$, is needed. Note, however, that $c_{7}$ depends on true anomaly, $\alpha$. As shown by Neugebauer [1975, 112-115], the parallax at syzygy $\pi_{s}$ is then:

$$
\pi_{s}=\mathrm{c}_{3}(z)+\mathrm{c}_{7}(\alpha) \cdot \mathrm{c}_{4}(z) .
$$

In Table 5 [p. 16 below], in addition to the column for the argument, there are four columns, all concerning the Moon at quadrature. The entries in columns 6,8 , and 9 are given in minutes of arc; whereas those in column 5 are displayed in degrees. As was the case with column 3 for syzygy, column $\mathrm{c}_{5}$ is a function of the zenith distance $\mathrm{z}$ (found in $\mathrm{c}_{1}$ ), and yields the 


\begin{tabular}{|c|c|c|c|c|}
\hline \multicolumn{2}{|c|}{$\begin{array}{l}\mathrm{c}_{1} \\
\left(^{\circ}\right)\end{array}$} & \multirow{2}{*}{$\begin{array}{c}c_{3} \\
\left(^{\prime}\right) \\
0 ; 28\end{array}$} & \multirow{2}{*}{$\begin{array}{r}c_{4} \\
\left({ }^{\prime}\right) \\
0 ; 5\end{array}$} & \multirow{2}{*}{$\begin{array}{r}\mathrm{c}_{7} \\
\left(^{\prime}\right) \\
0 ; 1\end{array}$} \\
\hline 1 & 359 & & & \\
\hline$\ldots$ & & & & \\
\hline 30 & 330 & $14 ; 0$ & $2 ; 43^{\mathrm{a}}$ & $3 ; 43$ \\
\hline$\ldots$ & & & & \\
\hline 60 & 300 & $27 ; 5$ & $5 ; 16^{b}$ & $14 ; 4$ \\
\hline$\cdots$ & & & & \\
\hline 90 & 270 & $38 ; 7$ & $7 ; 25$ & $28 ; 41$ \\
\hline$\ldots$ & & & & \\
\hline 120 & 240 & $46 ; 38$ & $9 ; 2$ & $43 ; 58$ \\
\hline$\cdots$ & & & & \\
\hline 150 & 210 & $51 ; 44$ & $9 ; 59$ & $55 ; 40$ \\
\hline$\cdots$ & & & & \\
\hline 180 & 180 & $53 ; 26$ & $10 ; 14$ & $60 ; 0$ \\
\hline
\end{tabular}

Table 4. Bianchini's lunar parallax at syzygy (excerpted)

lunar parallax when the Moon is at the apogee of the epicycle at quadrature. Analogously, column $\mathrm{c}_{6}$, also a function of the zenith distance, provides the increment to be applied to an entry in $c_{5}$ to obtain the parallax at perigee. For intermediary situations, there is also a column here for the minutes of proportion, $\mathrm{c}_{8}$, which depends on true anomaly $\alpha$. The parallax at quadrature $\pi_{q}$ is then:

$$
\pi_{q}=\mathrm{c}_{5}(z)+\mathrm{c}_{8}(\alpha) \cdot \mathrm{c}_{6}(z) .
$$

Equations (5) and (6) serve as the extremes for all situations between syzygy, where the mean elongation of the Sun and the Moon is $0^{\circ}$, and quadrature, where the mean elongation is $90^{\circ}$. For intermediary situations, it is necessary to introduce an interpolation scheme, column 9, with entries given in minutes as a function of mean elongation, $\bar{\eta}$. The 3-variable function for total lunar parallax thus becomes

$$
\pi=\pi_{s}+\mathrm{c}_{9}(\bar{\eta}) \cdot\left(\pi_{q}-\pi_{s}\right) .
$$

Use of Tables 1 [p. 8 above], 4 , and 5 [p. 16 below] together makes it possible to compute the longitudinal $\pi_{\lambda}$ and latitudinal $\pi_{\beta}$ components of total lunar 
parallax $\pi$ [see Figure 4, p. 17 below]. Since $\pi\left(=\operatorname{arc} M M^{\prime}\right)$ is small, one may apply plane rather than spherical trigonometry, without introducing significant errors, as Ptolemy explains [Alm. 5.19: see Toomer 1984, 266 with Neugebauer 1975, 116]:

$$
\pi_{\lambda}=\pi \cos \gamma \text { and } \pi_{\beta}=\pi \sin \gamma,
$$

where $\gamma$ is the angle between the ecliptic and the meridian.

\begin{tabular}{rccrrr} 
& $\begin{array}{c}\mathrm{c}_{1} \\
\left(^{\circ}\right)\end{array}$ & $\begin{array}{c}\mathrm{c}_{5} \\
\left(^{\circ}\right)\end{array}$ & $\begin{array}{r}\mathrm{c}_{6} \\
\left(^{\prime}\right)\end{array}$ & $\begin{array}{r}\mathrm{c}_{8} \\
\left(^{\prime}\right)\end{array}$ & $\begin{array}{c}\mathrm{c}_{9} \\
\left(^{\prime}\right)\end{array}$ \\
\hline 1 & 359 & $0 ; 0,42$ & $0 ; 13$ & $0 ; 2$ & $0 ; 2$ \\
$\ldots$ & & & & & \\
30 & 330 & $0 ; 20,38$ & $6 ; 35$ & $3 ; 31$ & $4 ; 48$ \\
$\ldots$ & & & & & \\
60 & 300 & $0 ; 39,52^{\mathrm{a}}$ & $12 ; 31$ & $13 ; 36$ & $17 ; 21$ \\
$\ldots$ & & & & & \\
90 & 270 & $0 ; 56,3$ & $17 ; 41$ & $28 ; 1$ & $33 ; 9$ \\
$\ldots$ & & & & & \\
120 & 240 & $1 ; 8,24$ & $21 ; 29$ & $43 ; 24^{\mathrm{b}}$ & $47 ; 21$ \\
$\ldots$ & & & & & \\
150 & 210 & $1 ; 15,51$ & $23 ; 35$ & $55 ; 26^{\mathrm{c}}$ & $56 ; 46$ \\
$\ldots$ & & & & & \\
180 & 180 & $1 ; 18,7$ & $24 ; 10$ & $60 ; 0$ & $60 ; 0$
\end{tabular}

a MSS BC, P2, and Paris 7271read 0;39,57, and the entry in MS C1is blank.

b MS BC reads 42;24.

c MS Va reads $55 ; 27$.

Table 5. Bianchini's lunar parallax at quadrature (excerpted)

By accepting Ptolemy's parameters for the Moon in his parallax table, Bianchini was implicitly adhering to his predecessor's approach to the variation in lunar distance from the Earth. Some astronomers, notably Levi ben Gerson (d. 1344) and Ibn al-Shātir (d.1375), had already noticed that, with Ptolemy's premises, the Moon-Earth distance varies from 33;33 to 64;10 terrestrial radii $[A l m .5 .17]$, thus suggesting that the Moon is twice the size in diameter at quadrature than at syzygy, contrary to observation [Goldstein 1997, 17; Saliba 1996, 102]. Regiomontanus was also aware of this problem. 


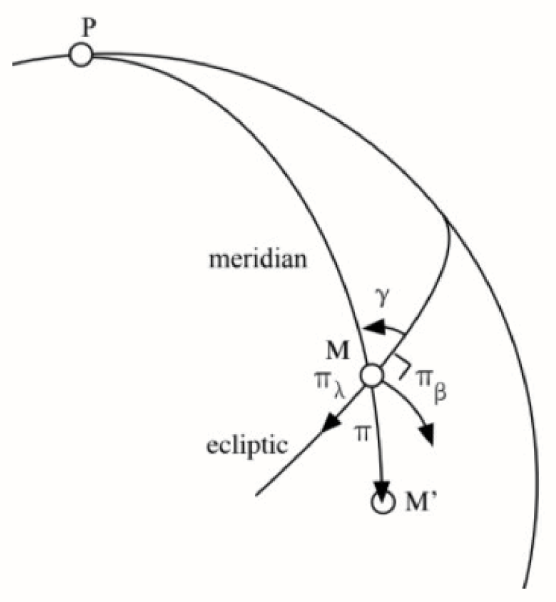

Figure 4. The components of total lunar parallax

In answering a letter he had received from Bianchini on 11 February 1464, he writes:

And if the moon has an eccentric and an epicycle in the way that has been claimed [by Ptolemy and his followers], it will follow necessarily that in a particular position the moon appear [in area] about four times greater than in another position, other things being in the same condition. [Swerdlow 1990, 174]

This variation was further emphasized by Regiomontanus in book 5, chapter 22 of his Epitome, printed in 1496:

But it is remarkable that when the moon is in quadrature in the perigee of the epicycle, it does not appear so large [i.e., $0 ; 56,22^{\circ}$ ] in diameter since if the entire moon were illuminated it should appear four times the size (i.e., in area) that it appears in opposition when it is at the apogee of the epicycle. [Swerdlow 1973, 462]

4. Table for the lunar diameter and velocities

Following the order in the Almagest, after parallax Bianchini turns to the apparent diameters of the bodies involved in the computation of eclipses and presents a table for the lunar diameter, to which he adds columns for lunar velocities. Table 6 [p. 18 below] displays an excerpt taken from MS C1 that gives velocities with a higher precision than in the other manuscripts that we have examined.

In MS $\mathrm{C}_{1}$, the entries for both velocities, in anomaly and in argument of latitude, are given to thirds, and in MS BC only to minutes; the entry for $1 \mathrm{~h}$ 


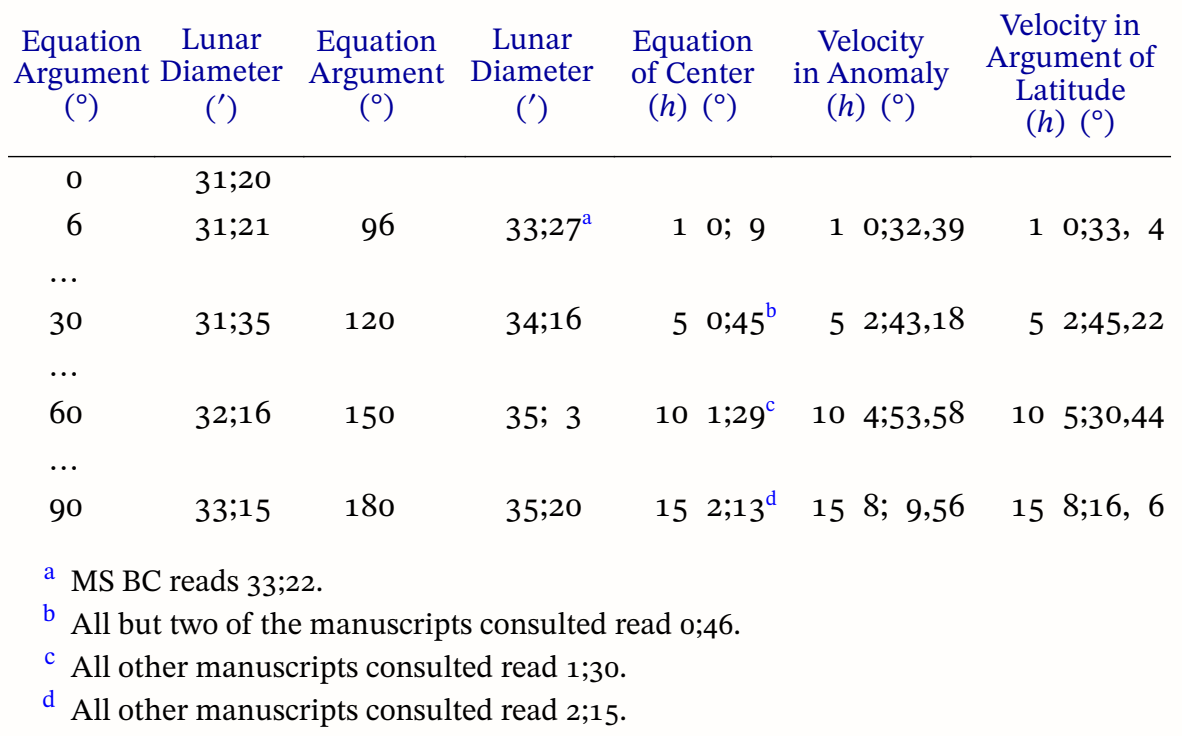

Table 6. Bianchini's table for lunar diameter and velocities (excerpted)

in MS Cracow is $0 ; 32,39,44^{\circ} / \mathrm{h}$, corresponding to the Alfonsine daily mean velocity in anomaly, $13 ; 3,53,57,30^{\circ} / \mathrm{d}$. MSS BC and P2 add a column for lunar latitude with a maximum value of $5^{\circ}$, as in the Almagest.

In this table, the argument is displayed at intervals of $6^{\circ}$ from $0^{\circ}$ to $180^{\circ}$, and the entries for the lunar diameter are given in minutes and seconds. The extremal values, $0 ; 31,20^{\circ}$ and $0 ; 35,20^{\circ}$, are indeed those found in the canons to chapters 9 and 10 of the Tabulae eclypsium. They also agree with those in Ptolemy's Alm. 5.14 and 6.5, although Ptolemy did not compile a full table for the lunar diameter [Toomer 1984, 252-254, 284]. From these extremal values, the rest of the entries may be recomputed using an auxiliary table of corrections, $\mathrm{c}(\alpha)$, such as that in Alm. 6.8, for interpolating between apogee and perigee in lunar eclipses [Toomer 1984, 308]. The entries for the lunar diameter may be computed from the expression

$$
0 ; 31,20+c(\alpha) \cdot(0 ; 35,20-0 ; 31,20),
$$

that is,

$$
0 ; 31,20+\mathrm{c}(\alpha) \cdot 0 ; 4
$$

Table 7 [p. 19 below] displays the results. 


\begin{tabular}{rccc}
$\alpha$ & $c(\alpha)$ & $\begin{array}{c}\text { Lunar } \\
\text { Diameter }\end{array}$ & Text \\
\hline 30 & $0 ; 4,1$ & $0 ; 31,36$ & $0 ; 31,35$ \\
60 & $0 ; 14,0$ & $0 ; 32,16$ & $0 ; 32,16$ \\
90 & $0 ; 28,42$ & $0 ; 33,15$ & $0 ; 33,15$ \\
120 & $0 ; 44,0$ & $0 ; 34,16$ & $0 ; 34,16$ \\
150 & $0 ; 55,32$ & $0 ; 35,2$ & $0 ; 35,3$ \\
180 & $0 ; 60,0$ & $0 ; 35,20$ & $0 ; 35,20$
\end{tabular}

Table 7. Recomputation of the entries for the lunar diameter

In chapter 19, Bianchini explains that Ptolemy had derived the extremal values of the lunar diameter, $0 ; 31,20^{\circ}$ at apogee and $0 ; 35,20^{\circ}$ at perigee $[\mathrm{Alm}$. 6.5], from the data of two eclipses in each case and adds that al-Battānī applied the same procedure. Mirroring the Almagest, Bianchini proceeds analogously, and in chapter 20 of his Tabulae eclypsium, ${ }^{7}$ he derives the extremal values of the lunar diameter at apogee and perigee from the data of four lunar eclipses. Note that nowhere in chapter 20 does Bianchini mention any observation or computation of these eclipses. Rather, he only says that he "considered" four eclipses. The information provided is displayed in Table 8 [p. 20 below].

To derive these two values of the apparent diameter of the Moon, Bianchini follows Ptolemy's procedure as presented in Alm. 5.14 for the value at apogee, and Alm. 6.5 for the value at perigee [Toomer 1984, 253-254, 283-285, resp.]. However, Bianchini's method differs slightly from Ptolemy's, as explained by Neugebauer [1975, 104-108, 1235]: Bianchini considers the lunar latitude (perpendicular to the ecliptic), whereas Ptolemy considers quantities on the great circle perpendicular to the lunar orb, thereby introducing a small difference.For the Moon at apogee, Bianchini uses the lunar eclipses of 1440 and 1451, when the Moon was close to its epicyclic apogee, and the anomaly was thus close to $0^{\circ}$. For the Moon at perigee, he uses the eclipses dated 1448 and 1455 , when the lunar anomaly was close to $180^{\circ}$. The entries for the Sun, the Moon, mean anomaly, arguments of latitude and latitude were not observed; rather, they were computed from the time of mid-eclipse whether observed or computed.

7 A transcription of this chapter is found in Thorndike 1950, 175-176. 
(1)

(2)

(3)

(4)

16 Feb $1440 \quad 12$ Sep $1448 \quad 13$ Jul $1451 \quad 1$ May 1455

\begin{tabular}{|c|c|c|c|c|}
\hline Time & $16 ; 43 \mathrm{~h}$ & $11 ; 3 \mathrm{~h}$ & $12 ; 16 \mathrm{~h}$ & $12 ; 28 \mathrm{~h}$ \\
\hline Sun & $\operatorname{Psc} 8 ; 3^{\circ}$ & Vir $28 ; 47^{\circ}$ & Cnc $29 ; 7^{\circ}$ & Tau 19;39 \\
\hline Moon & $\operatorname{Vir} 8 ; 3^{\circ}$ & $\operatorname{Psc} 28 ; 47^{\circ}$ & Cap 29; $7^{\circ}$ & $\operatorname{Sco} 19 ; 39^{\circ}$ \\
\hline Mean anomaly & $5 ; 54^{\circ}$ & “3.23.45” "a & $34 ; 12^{\circ}$ & “2.48.40”b \\
\hline Arg. latitude & $5 ; 4^{\circ}$ & $11 ; 28^{\circ}$ & $6 ; 34^{\circ}$ & $10 ; 35^{\circ}$ \\
\hline Latitude & $0 ; 26,27^{\circ}$ & $0 ; 39,32^{\circ \mathrm{c}}$ & $0 ; 26,27^{\circ}$ & $0 ; 55,1^{\circ}$ \\
\hline Magnitude & $11^{1 / 2}$ & $1 ; 25$ & $8 ; 34$ & $2 ; 57$ \\
\hline \multicolumn{5}{|c|}{ a That is, $203 ; 45^{\circ}$. } \\
\hline \multicolumn{5}{|c|}{${ }^{b}$ That is, $168 ; 40^{\circ}$. } \\
\hline
\end{tabular}

Table 8. Data of the four eclipses used by Bianchini to determine the lunar diameter

At apogee (eclipses 1 and 3), Bianchini transforms the two lunar arguments of latitude into latitude and obtains $0 ; 26,27^{\circ}$ and $0 ; 34,16^{\circ}$, respectively. For this he uses a table for lunar latitude with a maximum of $5^{\circ}$. Actually, for the first eclipse, he should have obtained $0 ; 26,28^{\circ}$. Then, Bianchini finds the difference between these two values and correctly obtains $0 ; 7,49^{\circ}$. For the difference in magnitude, he correctly obtains 2;56 digits (where the lunar diameter is 12 digits), which he takes to be equal to $11 / 45$, given that $2 ; 56 \cdot 45=132=12 \cdot 11$. He then divides the difference in latitude by the difference in the eclipsed diameters: $0 ; 7,49^{\circ} /(11 / 45)$. The result, $0 ; 31,59^{\circ}$, is not mentioned, and Bianchini indicates that had the Moon been precisely at apogee, the diameter would have been that found by Ptolemy, explicitly given as $0 ; 31,20^{\circ}$.

At perigee (eclipses 2 and 4 ), the difference in latitude is $0 ; 4,31^{\circ}$. This value is correctly computed if one considers the latitude of eclipse 1 to be $0 ; 59,32^{\circ}$ rather than $0 ; 39,32^{\circ}$, as mistakenly given in the text. The resulting difference in magnitude is $1 ; 32$, which is said to be $23 / 180$ of the total diameter. Indeed, $1 ; 32 \cdot 180=276=12 \cdot 23$. As was the case above, the result, $0 ; 35,21^{\circ}$, is not mentioned. Instead, we are told that it is close to Ptolemy's value, explicitly given as $0 ; 35,20^{\circ}$. 
It would thus seem that Bianchini was just confirming Ptolemy's data and justifying his use of them. In a more general way, Bianchini seems here to be updating the Almagest by appealing to recent eclipses.

We now turn to the three other tabulated quantities in Table 6 [p. 18 above] (equation of center, hourly velocity in anomaly, and hourly velocity in argument of anomaly). In all three cases, the argument ranges from 1 to 15 and is given in hours.

The equation of center is given in degrees and minutes, and indeed in MS C1 the 15 values displayed correspond to the Alfonsine equation of center for arguments $1^{\circ}$ to $15^{\circ}$. As for the columns for the lunar velocities in anomaly and in argument of latitude, the entries are displayed in degrees, minutes, and seconds per hour in MS C1. But in the other manuscripts examined, they are rounded to minutes. The entries for one hour, $0 ; 32,39^{\circ} / \mathrm{h}$ (anomaly) and $0 ; 33,4^{\circ} / \mathrm{h}$ (argument of latitude), or better, those derived from 15 hours $\left(0 ; 32,39,44^{\circ} / \mathrm{h}\right.$ and $0 ; 34,4,24^{\circ} / \mathrm{d}$, respectively), are rounded values of the Alfonsine daily mean velocities in anomaly, $13 ; 3,53,57,30^{\circ} / \mathrm{d}$, and in argument of latitude, $13 ; 13,45,39,22^{\circ} / \mathrm{d}$, respectively. In the case of the lunar velocity in anomaly, the use of different precision in the values for one hour in MSS $\mathrm{C} 1$ and $\mathrm{BC}$ is the reason that the entries from 6 to 11 are increased by $0 ; 1^{\circ}$ and those from 12 to 15 are increased by $0 ; 2^{\circ}$.

\section{Other tables}

In addition to the three tables reviewed above, Bianchini included five tables for the digits of eclipse. Two of them are for solar eclipses and two others for lunar eclipses, each at greatest distance (ad longitudinem longiorem) as well as at least distance (ad longitudinem propinquiorem). The fifth table is presented in three columns, one for the argument (the fraction of the diameter), and one for each luminary that displays the eclipsed part of its disk. The format is the same as in Ptolemy, al-Battānī, the Toledan Tables, and the Parisian Alfonsine Tables.

The argument in the four tables for the digits of eclipse is the argument of lunar latitude, the variable used in the Almagest and in the zij of al-Battānī, in contrast to the lunar latitude, which is the variable in Ptolemy's Handy Tables and in the zij of al-Khwārizmī. Moreover, comparison with the tables in previous sets shows that Bianchini followed most closely Alm. 6.8. There is, however, an obvious difference: Bianchini employs the argument of lunar latitude starting at the lunar node, whereas in the Almagest it is increased by $90^{\circ}$ or $270^{\circ}$. The steps of the argument are the same for Bianchini and Ptolemy: $0 ; 30^{\circ}$ for both solar tables and the Moon at greatest distance, and 
Argument of Latitude

\begin{tabular}{|c|c|c|c|c|c|c|}
\hline \multicolumn{2}{|c|}{$\begin{array}{l}\text { North } \\
\left(^{\circ}\right)\end{array}$} & \multicolumn{2}{|c|}{$\begin{array}{l}\text { South } \\
\left({ }^{\circ}\right)\end{array}$} & \multirow{2}{*}{$\begin{array}{c}\begin{array}{c}\text { Magn- } \\
\text { itude } \\
(p)\end{array} \\
0 ; 0\end{array}$} & \multirow{2}{*}{$\begin{array}{c}\begin{array}{c}\text { Immer- } \\
\text { sion } \\
(')\end{array} \\
0 ; 0\end{array}$} & \multirow{2}{*}{$\begin{array}{c}\begin{array}{c}\text { Half } \\
\text { Totality } \\
\left({ }^{\prime}\right)\end{array} \\
0 ; 0\end{array}$} \\
\hline $12 ; 16$ & $167 ; 44$ & $192 ; 16$ & $347 ; 44$ & & & \\
\hline $11 ; 42$ & $168 ; 18$ & $191 ; 42$ & $348 ; 18$ & $1 ; 0$ & $19 ; 2$ & $0 ; 0$ \\
\hline $11 ; 8$ & $168 ; 52$ & $191 ; 8$ & $348 ; 52$ & $2 ; 0$ & $26 ; 45^{\mathrm{a}}$ & $0 ; 0$ \\
\hline $10 ; 34$ & $169 ; 26$ & 190;14 & $349 ; 26$ & $3 ; 0$ & $32 ; 17$ & $0 ; 0$ \\
\hline $10 ; 0$ & $170 ; 0$ & 190; 0 & $350 ; 0$ & $4 ; 0$ & $36 ; 51$ & $0 ; 0$ \\
\hline $9 ; 26$ & $170 ; 34$ & 189;26 & $350 ; 34$ & $5 ; 0$ & $40 ; 41$ & $0 ; 0$ \\
\hline $8 ; 52$ & 171,8 & $188 ; 52$ & $351 ; 8$ & $6 ; 0$ & $44 ; 0$ & $0 ; 0$ \\
\hline $8 ; 18$ & $172 ; 42$ & $188 ; 18$ & $351 ; 42$ & $7 ; 0$ & $46 ; 51$ & $0 ; 0$ \\
\hline $7 ; 44$ & $172 ; 16$ & $187 ; 44$ & $352 ; 16$ & $8 ; 0$ & $49 ; 33$ & $0 ; 0$ \\
\hline $7 ; 10$ & $172 ; 50$ & $187 ; 10$ & $352 ; 50$ & $9 ; 0$ & $51 ; 40$ & $0 ; 0$ \\
\hline $6 ; 36$ & $173 ; 24$ & $186 ; 36$ & $353 ; 24$ & $10 ; 0$ & $53 ; 40$ & $0 ; 0$ \\
\hline $6 ; 2$ & $173 ; 58$ & $186 ; 2$ & $353 ; 48$ & $11 ; 0$ & $55 ; 33$ & $0 ; 0$ \\
\hline $5 ; 28$ & $174 ; 32$ & $185 ; 28$ & $354 ; 32$ & $12 ; 0$ & $56 ; 59$ & $0 ; 0$ \\
\hline $4 ; 54$ & $175 ; 6$ & $184 ; 54$ & $355 ; 6$ & $13 ; 0$ & $45 ; 50$ & $12 ; 31$ \\
\hline $4 ; 20$ & $175 ; 40$ & $184 ; 20$ & $355 ; 40$ & $14 ; 0$ & $42 ; 18$ & $17 ; 35$ \\
\hline $3 ; 46$ & $176 ; 14$ & $183 ; 46$ & $356 ; 24$ & $15 ; 0$ & $40 ; 3$ & $20 ; 30^{\mathrm{b}}$ \\
\hline $3 ; 12$ & $176 ; 48$ & $183 ; 12$ & $356 ; 48$ & $16 ; 0$ & $38 ; 28$ & $22 ; 58$ \\
\hline $2 ; 38$ & $177 ; 22$ & $182 ; 38$ & $357 ; 22$ & $17 ; 0$ & $37 ; 19$ & $24 ; 48$ \\
\hline $2 ; 4$ & $177 ; 56$ & $182 ; 4$ & $357 ; 56$ & $18 ; 0$ & $36 ; 27$ & $26 ; 14$ \\
\hline $1 ; 30$ & $178 ; 30$ & $181 ; 30$ & $358 ; 30$ & $19 ; 0$ & $35 ; 57$ & $27 ; 12$ \\
\hline $0 ; 56$ & $179 ; 4$ & $180 ; 56$ & $359 ; 4$ & $20 ; 0$ & $35 ; 23^{c}$ & $27 ; 53^{d}$ \\
\hline $0 ; 22$ & $179 ; 38$ & $180 ; 22$ & $359 ; 38$ & $21 ; 0$ & $35 ; 23$ & $28 ; 14$ \\
\hline $0 ; 0$ & 180; 0 & 180; 0 & $360 ; 0$ & $21 ; 36$ & $35 ; 22$ & $28 ; 17$ \\
\hline $\begin{array}{ll} & \text { a } \\
\text { b } & M s \\
\text { c } & M s \\
\text { d } & M s\end{array}$ & $\begin{array}{l}\text { eads } 54 \text {. } \\
\text { eads } 31 \text {. } \\
\text { eads } 33 \text {. } \\
\text { eads } 13 \text { ? }\end{array}$ & & & & & \\
\hline
\end{tabular}

Table 9. Lunar eclipses at least distance in MS BC 
$0 ; 34^{\circ}$ for the Moon at least distance. The maximum values of the argument also agree for the $\operatorname{Sun}\left(6^{\circ}\right.$ and $\left.6 ; 24^{\circ}\right)$, but not for the Moon $\left(10 ; 48^{\circ}\right.$ and $12 ; 12^{\circ}$ for Ptolemy; $10 ; 51^{\circ}$ and $12 ; 16^{\circ}$ for Bianchini). This shows that the values of the argument in Bianchini's lunar tables differ from those in the Almagest. Table 9 [p. 22 above] displays one of Bianchini's two tables for the Moon.

All four tables have columns for the magnitude of the eclipse in digits of the diameter. For immersion, that is, the arc between first contact and second contact (beginning of totality), the entry is in minutes of arc. The two tables for lunar eclipses add a column for the half-duration of totality, that is, the arc from second contact to mid-eclipse, which is also given in minutes of arc. Note that these two "durations" are actually arcs and are, therefore, expressed in minutes of arc.

The entries in Bianchini's lunar eclipse tables differ slightly from those in the Almagest. Table 10 [p. 24 below] displays selected entries for least distance by the two authors. It should be noted that even though the values of the argument differ-Bianchini chose to have as maximum entry $12 ; 16^{\circ}$ instead of the $12 ; 12^{\circ}$ in the Almagest - the magnitudes are common to both Bianchini and Ptolemy. As a matter of fact, magnitude is the underlying argument in tables for the digits of eclipses.

The differences between the corresponding entries of both authors do not reflect copyists' errors; rather, they suggest that Bianchini recomputed the entries in his table. In order to verify this claim and to recompute the entries in Table 9, consider Figure 5 [p. 25 below]. When using Ptolemy's values for the radii of the Moon $\left(0 ; 17,40^{\circ}\right)$ and the Earth's shadow $\left(0 ; 46^{\circ}\right)$ at perigee, and following Ptolemy's procedure, one can derive the entries for the arcs of immersion and half-duration of totality. The first step consists in defining a quantity, $\mu$, proportional to $m$, the magnitude of the lunar eclipse, $\mu=m(d / 12)$, where $d$ is the lunar diameter. Let us call $r$ and $s$ the radii of the Moon and the Earth's shadow, respectively, and $S$ the center of the shadow circle at the middle of the eclipse, when $m$ is maximum. The distance between $S$ and the center of the Moon at first contact, $A$, is $r+s$, and the distance between $S$ and the center of the Moon at mid-eclipse, $B$, is $s-(\mu-r)$. Now, let us call $C$ the center of the Moon at the beginning of totality. Then $S C=s-r$. In the right triangle $S B C, B C$ is the distance called half-duration of the eclipse and displayed in Table 9. In the right triangle $S B A, B A$ is the sum of the half-duration and arc $C A$, called immersion, also displayed in Table 9. As an example, let us consider the entries for magnitude 18;0, corresponding to arguments of latitude $2 ; 0^{\circ}$ in the case of the Almagest and $2 ; 4^{\circ}$ in the case 


\begin{tabular}{|c|c|c|c|c|c|c|}
\hline \multicolumn{2}{|c|}{ Argument of Latitude } & \multirow[t]{2}{*}{$\begin{array}{l}\text { Magni- } \\
\text { tude }\end{array}$} & \multicolumn{2}{|c|}{ Immersion } & \multicolumn{2}{|c|}{ Half Totality } \\
\hline Bianchini & Ptolemy & & Bianchini & Ptolemy & Bianchini & Ptolemy \\
\hline $12 ; 16$ & $12 ; 12$ & $0 ; 0$ & $0 ; 0$ & $0 ; 0$ & $0 ; 0$ & $0 ; 0$ \\
\hline $11 ; 42$ & $11 ; 38$ & $1 ; 0$ & $19 ; 2$ & $19 ; 9$ & $0 ; 0$ & $0 ; 0$ \\
\hline $10 ; 0$ & $9 ; 56$ & $4 ; 0$ & $36 ; 51$ & $36 ; 53$ & $0 ; 0$ & $0 ; 0$ \\
\hline $\begin{array}{r}\ldots \\
7 ; 44 \\
\ldots\end{array}$ & $7 ; 40$ & $8 ; 0$ & $49 ; 33$ & $49 ; 25$ & $0 ; 0$ & $0 ; 0$ \\
\hline $5 ; 28$ & $5 ; 24$ & $12 ; 0$ & $56 ; 59$ & $56 ; 59$ & $0 ; 0$ & $0 ; 0$ \\
\hline $\begin{array}{r}4 ; 54 \\
\ldots\end{array}$ & $4 ; 50$ & $13 ; 0$ & $45 ; 50$ & $45 ; 47$ & $12 ; 31$ & $12 ; 34$ \\
\hline $\begin{array}{r}2 ; 38 \\
\ldots\end{array}$ & $2 ; 34$ & $17 ; 0$ & $37 ; 19$ & $37 ; 20$ & $24 ; 48$ & $24 ; 49$ \\
\hline $0 ; 22$ & $0 ; 18$ & $21 ; 0$ & $35 ; 23$ & $35 ; 22$ & $28 ; 14$ & $28 ; 12$ \\
\hline $0 ; 0$ & $0 ; 0$ & $21 ; 36$ & $35 ; 22$ & $35 ; 20$ & $28 ; 17$ & $28 ; 16$ \\
\hline
\end{tabular}

of the Tabulae eclypsium. This example is of special interest because the entries given by the two authors disagree to the greatest extent: $0 ; 10^{\prime}$ for the arc of immersion and $0 ; 13^{\prime}$ for the arc of half-duration of totality. When $m=18$, then $\mu=m(d / 12)=0 ; 53$. Therefore,

$$
S B=s-(\mu-r)=0 ; 46^{\circ}-\left(0 ; 53^{\circ}-0 ; 17,40^{\circ}\right)=0 ; 10,40^{\circ} .
$$

Now,

$$
S C=s-r=0 ; 46^{\circ}-0 ; 17,40^{\circ}=0 ; 28,20^{\circ}
$$

and

$$
S A=s+r=0 ; 46^{\circ}+0 ; 17,40^{\circ}=1 ; 3,40^{\circ} .
$$

Hence, $B C=\sqrt{\left(S C^{2}-S B^{2}\right)}=0 ; 26,15^{\circ}$ is the computed value for the halfduration of the eclipse, and it is to be compared with the entries given by Ptolemy $\left(26 ; 1^{\prime}\right)$ and Bianchini $\left(26 ; 14^{\prime}\right)$. As for the immersion, we first compute

$$
B A=\sqrt{\left(S A^{2}-S B^{2}\right)}=1 ; 2,46^{\circ}
$$

and subtract from it the half-duration previously computed, $0 ; 26,15^{\circ}$ to obtain $0 ; 36,31^{\circ}$. This value is to be compared with the entries given by Ptolemy 


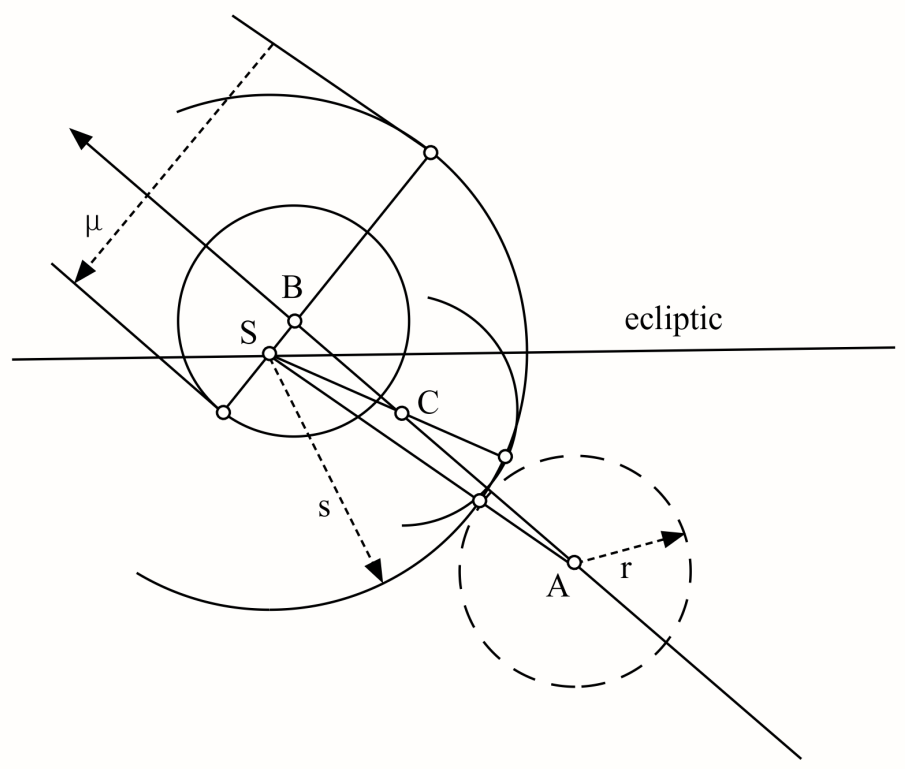

Figure 5. Arcs of immersion and half-duration of a lunar eclipse

$\left(36 ; 37^{\prime}\right)$ and Bianchini $\left(36 ; 27^{\prime}\right)$. In both cases, the recomputed values are closer to Bianchini's entries.

This is not always so. For example, when magnitude $m=14 ; 0$, computation for half-duration yields $0 ; 17,17^{\circ}$. The entry in Ptolemy's table is exactly $17 ; 17^{\prime}$, whereas Bianchini gives 17;35'. Other examples indicate that the two authors computed the entries in their respective tables accurately, for the residuals in all cases only affect the seconds. It is impossible to decide who did a better job because the differences between their results are so small that they are obscured by a long tradition of possible copyists' errors in the transmission of the tables.

The fifth table displays the eclipsed parts of the solar and lunar disks. In this instance, the argument is the fraction of the diameter in digits with a maximum value of 12 , and the entries for the two luminaries are integrated in a single table [see Table 11, p. 26 below], in contrast to most of the previous tables for the same purpose. 


\begin{tabular}{crr}
$\begin{array}{c}\text { Diameter } \\
\text { Linear } \\
\text { digits }\end{array}$ & $\begin{array}{c}\text { Sun } \\
\text { Area } \\
\text { digits }\end{array}$ & $\begin{array}{r}\text { Moon } \\
\text { Area } \\
\text { digits }\end{array}$ \\
\hline 1 & $0 ; 20$ & $0 ; 30$ \\
2 & $1 ; 0$ & $1 ; 20$ \\
3 & $1 ; 40$ & $2 ; 4$ \\
4 & $2 ; 40$ & $3 ; 10$ \\
5 & $3 ; 40$ & $4 ; 20$ \\
6 & $4 ; 48$ & $5 ; 30$ \\
7 & $5 ; 50$ & $6: 45$ \\
8 & $7 ; 0$ & $8 ; 0$ \\
9 & $8 ; 20$ & $9 ; 10$ \\
10 & $9 ; 40$ & $10 ; 20$ \\
11 & $10 ; 50$ & $11 ; 20$ \\
12 & $12 ; 0$ & $12 ; 0$
\end{tabular}

Table 11. The eclipsed part of the solar and lunar disks in MS BC

This table appears, with numerous variants, in many sets of astronomical tables, thus making it problematic to determine the direct antecedent for Bianchini's table [see, e.g., Chabás and Goldstein 2012, 175].

6. Detailed computations of a solar and a lunar eclipse in $1460^{8}$

The computation of a solar eclipse to be observed in the future in Ferrara, in July 1460 , begins in chapter 24 and ends in chapter 35 . The initial step is to determine the true conjunction of the Sun and the Moon, by first computing their mean conjunction using tables for the radices and mean motions for conjunction integrated in Bianchini's set of planetary tables [Chabás and Goldstein 2009, 79-85, Tables 57-62]. The results for mean conjunction are:

Time: July 18,1460 at $1 ; 6 \mathrm{~h}$ after noon;

Mean longitude of both luminaries: "2.5.26" $\left(=125 ; 26^{\circ}\right)$;

Mean lunar anomaly: "g.211. m.7." $\left(=211 ; 7^{\circ}\right)$;

Mean argument of lunar anomaly: "0.7.14" $\left(=7 ; 14^{\circ}\right)$.

The longitude of the solar apogee for 1460, taken from another table of his, is given as "1.30.48" $\left(=90 ; 48^{\circ}\right)$ [Chabás and Goldstein 2009, 40-41, Table

8 The base manuscript for this explanation is MS P1. For checking, we have used MSS $\mathrm{BC}, \mathrm{C}_{1}, \mathrm{P}_{4}$, and Va. 
8]; thus, the solar anomaly is "0.34.38" $\left(=34 ; 38^{\circ}\right)$. The use of signs of $60^{\circ}$ is maintained throughout the text, but the notation, as will be seen in other examples below, varies.

The next step is to determine the true positions of the Sun and the Moon at mean conjunction. For the Sun, Bianchini enters the appropriate table and finds its true longitude, $124 ; 16^{\circ}$, and the corresponding hourly solar velocity, 0;2,23\% / [Chabás and Goldstein 2009, 85-87, Table 63]. For the true position of the Moon at mean conjunction, he enters the appropriate table and obtains $128 ; 10^{\circ}$ for the lunar longitude and $0 ; 36,0^{\circ} / \mathrm{h}$ for the corresponding hourly lunar velocity [Chabás and Goldstein 2009, 87-91, Table 64]. The difference between the two true longitudes at mean conjunction is "g.3. m.54" $\left(=3 ; 54^{\circ}\right) .{ }^{9}$ He then finds the superatio, that is, the difference between the hourly velocities of the Moon and the Sun, 0;36, $0^{\circ} / \mathrm{h}-0 ; 2,23^{\circ} / \mathrm{h}$ $=0 ; 33,37^{\circ} / \mathrm{h}$, and divides the elongation found above, $3 ; 54^{\circ}$, by the superatio, yielding 6;59h (correctly: 6;57,39h). ${ }^{10}$ Bianchini then subtracts this amount from the time of mean conjunction, July 18,$1 ; 6 \mathrm{~h}$, and finds the time of true conjunction: July 17, 18; 7 h. The true longitude of the Sun at true conjunction follows:

$$
124 ; 16^{\circ}-6 ; 59 \mathrm{~h} \cdot 0 ; 2,23^{\circ} / \mathrm{h} \approx 123 ; 59^{\circ} .
$$

Analogously for the Moon, he obtains

$$
123 ; 59^{\circ}=128 ; 10^{\circ}-6 ; 59 \mathrm{~h} \cdot 0 ; 36,0^{\circ} / \mathrm{h} \text {. }
$$

We note that with the correctly rounded value $6 ; 58 \mathrm{~h}$ instead of $6 ; 59 \mathrm{~h}$, the results for the true positions of the Sun and the Moon would have been the same, 123;59 .

Then, Bianchini determines the mean argument of lunar latitude at true conjunction and finds 9;18 [Chabás and Goldstein 2009, 87-91, Table 64]. This is a mistake in MS P1 for 9;58 $8^{\circ}{ }^{11}$ Next he derives the true argument of latitude:

$$
9 ; 58^{\circ}-6 ; 59 \mathrm{~h} \cdot 0 ; 36,0^{\circ} / \mathrm{h}=5 ; 47^{\circ} \text {. }
$$

MSS $\mathrm{C}_{1}$ and Va disagree and give the result as $5 ; 45^{\circ}$. Bianchini comments that this value implies that the eclipse is possible.

For the computation of the position of the lunar node, Bianchini determines the motion of the center of the Moon in the time between mean and true syzygy, 6;59h, and finds $7 ; 0^{\circ}$ and its complement in $360^{\circ}, 353 ; 0^{\circ}$. He then

9 Note the change in notation.

10 All manuscripts examined have 6;59h.

${ }^{11}$ MS Va has the proper reading and MSS C1 and BC have 9;1 $8^{\circ}$ emended to $9 ; 58^{\circ}$. 
subtracts the argument of lunar latitude $5 ; 47^{\circ}$ from the lunar longitude $123 ; 59^{\circ}$ both at true conjunction and finds $118 ; 54^{\circ}$ (correctly: $118 ; 12^{\circ}$ ) for the longitude of the node at true conjunction. ${ }^{12}$

Analogously, from the mean lunar anomaly at mean conjunction, $211 ; 7^{\circ}$, Bianchini derives its value at true conjunction, 6;59h earlier. Rather than multiply this interval by the velocity in anomaly, Bianchini uses the table for lunar diameter and velocities [see Table 6, p. 18 above], listing multiples of the hourly velocity in anomaly $\left(0 ; 32,39^{\circ} / \mathrm{h}\right.$ or $\left.0 ; 32,39,44^{\circ} / \mathrm{h}\right)$. The entry found is then subtracted from the lunar anomaly at mean conjunction to obtain $207 ; 19^{\circ}$, the mean lunar anomaly at true conjunction. This has to be converted into a true anomaly. In the same table, called tabula gracilis in the text, the corresponding value for the equation of center is $1 ; 2^{\circ}$, which he subtracts from the previous one to get $206 ; 17^{\circ}$, the equated anomaly at true conjunction.

To close chapter 24, Bianchini summarizes the results obtained for true conjunction at Ferrara.

Time: 1460 "imperfecto", July 18 at 5;53 h before noon (“diebus non equatis") or at $5 ; 41 \mathrm{~h}$, after the equation of time is applied

True longitude of the luminaries: "g.3. m.59. leonis" $\left(=123 ; 59^{\circ}\right)^{13}$

Longitude of the lunar node: "g.28. m.14. cancri" $\left(=118 ; 14^{\circ}\right)$

Argument of lunar latitude: $5 ; 41^{{ }^{14}}$

True lunar anomaly: $206 ; 17^{\circ}$

Mean center: $5 ; 53^{\mathrm{O}_{15}}$

Motion of the Sun in an hour: $0 ; 2,23^{\circ} / \mathrm{h}$

Motion of the Moon in an hour: $0 ; 36,0^{\circ} / \mathrm{h}$

Lunar latitude: $+0 ; 30,1^{\circ}$

In the following chapters, Bianchini computes other quantities involved in this eclipse. Chapter 25 is devoted to the computation of the zenith distance of the Moon at the time of the eclipse. For that purpose, he uses several

12 MSS P1, P4, BC, and Va read 118;54 ${ }^{\circ}$ MS C1 reads $118 ; 14^{\circ}$. See also the values quoted at the end of chapter 24 , and chapter 33 , below.

13 Note a new variant in notation. The value mentioned above is $118 ; 54^{\circ}$ (correctly $118 ; 12^{\circ}$ ). As the digits 1 and 5 are easily confused in a humanist hand, it is likely that the scribe wrote " 28.54 " rather than " 28.14 ”. MS BC reads " 28.24 ".

14 The value mentioned above is $5 ; 47^{\circ}$ in MSS $\mathrm{P} 1, \mathrm{P} 4$, and $\mathrm{BC}$, but $5 ; 45^{\circ}$ in MS Va. Again, a confusion between the numerals for 1 and 5 is possible.

15 MS Va reads correctly $353^{\circ}$, as above. 


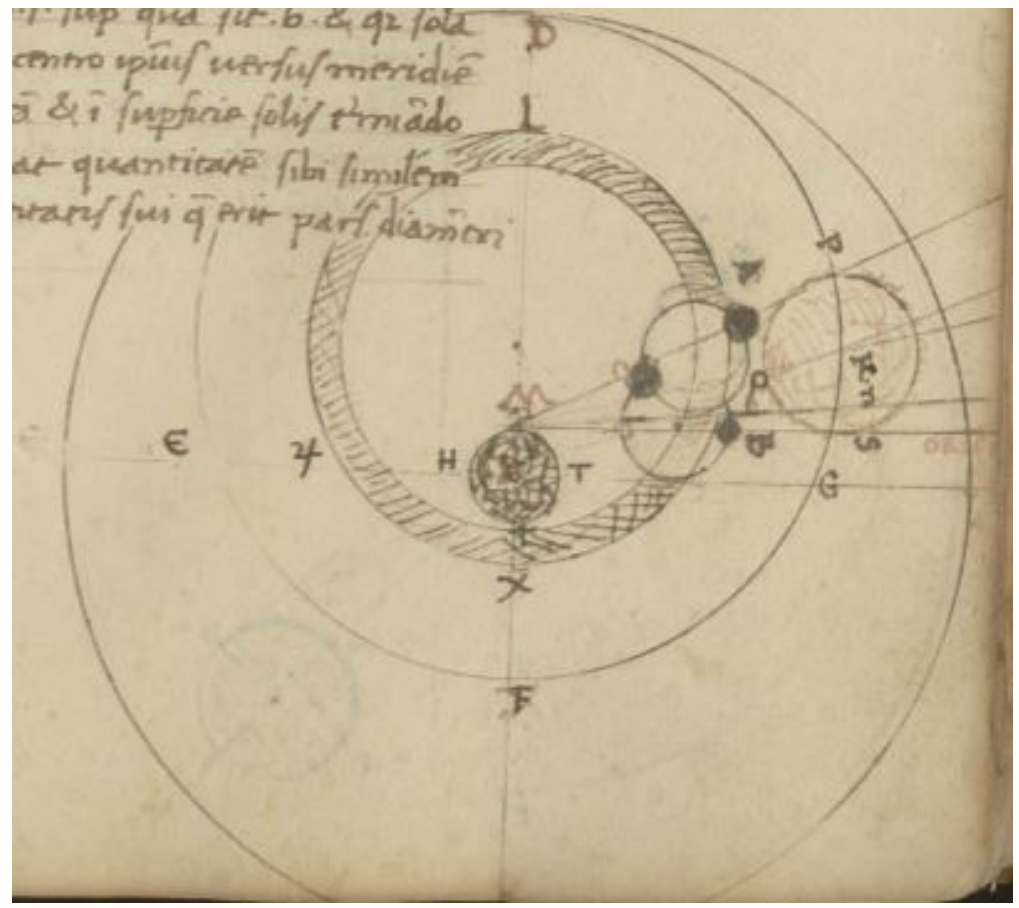

Figure 6. Solar eclipse, MS C1, 26r (chapter 5)

This manuscript is the only one, among those we have examined, to display diagrams for the solar and lunar eclipses in the Tabulae eclypsium [cf. Figure 7, p. 33 below].

tables: right ascension "ariete incipiente" (starting with Aries $0^{\circ}$ ), oblique ascension for $45^{\circ}$ (latitude of Ferrara), declination, and sine. The result is $73 ; 9^{\circ}$ for the lunar distance from the zenith.

In chapters 26 and 27, Bianchini deals with the computation of the eastern and western angles between the ecliptic and the local meridian, respectively. For the time of this eclipse, he uses a procedure equivalent to equation (2) described in section 1 [p. 4 above], and finds $151 ; 5^{\circ}$ for the eastern angle. Then, Bianchini gives instructions for computing the western angle when the eclipse occurs after noon by means of a table composed by Bianchini himself [see Table 1, p. 8 above].

Bianchini computes total parallax at the time of conjunction in chapter 28 , following a procedure analogous to equation (5) described in section 3 [p. 12 above]. He enters his table for lunar parallax at syzygy [see Table 4, p. 15 above] with twice the zenith distance for the entries diversitas $\left(c_{3}\right)$ 
and equatio $\left(\mathrm{c}_{4}\right)$ and with the true anomaly of the Moon for the minutes of proportion $\left(\mathrm{c}_{7}\right)$. The result for the total lunar parallax at syzygy is given as $60 ; 38^{\prime} \cdot{ }^{16}$

The determination of the longitudinal component of parallax is explained in chapter 29. Detailed instructions are given: take the eastern angle previously obtained $\left(151 ; 5^{\circ}\right)$ and find its cosine (52519); take the value of parallax $\left(60 ; 38^{\circ}\right)$ and find its sine (1057); multiply both numbers; discard from the product-55,512,583, no result is given — the four digits (figuras) to the right; divide the resulting number by 6 to obtain 925 ; and find 53;0' in the corresponding entry in the sine table. ${ }^{17}$ In addition to the convoluted instructions for "dividing by 60,000 " since the sine table is normed 60,000 , we are told that the cosine of the angle between the ecliptic and the meridian is to be multiplied by the sine of the parallax, not just by the parallax. This procedure indicates that Bianchini is applying spherical trigonometry to derive $\pi_{\lambda}$, in contrast to Ptolemy's procedure in Alm. 5.19. However, the result obtained for the longitudinal component of parallax, $53 ; 0^{\prime}$, can only be obtained if the sine function is not applied to the parallax.

Next, Bianchini transforms into time the parallax in longitude by dividing its value by the superatio, that is, the difference between the hourly velocities of the Moon and the Sun $\left(0 ; 33,37^{\circ} / \mathrm{h}\right)$, to obtain $1 ; 35 \mathrm{~h}$, which he adds to the time of the eclipse after the equation of time is applied, which was already found to be $5 ; 41 \mathrm{~h}$ before noon. Thus, Bianchini reports that the time of the "visible" conjunction is $7 ; 16 \mathrm{~h}$ before noon, and notes that this is a first equated time.

In chapters 30 and 31, Bianchini iterates the procedure to find the time of the eclipse. Having found the first equated time after taking parallax into account, he recomputes the new zenith distance of the Moon, finds the new eastern angle, and then the new parallax. This results in a new time of the eclipse, that is, a second equated time $(7 ; 13 \mathrm{~h})$. Another iteration leads to a third equated time $(7 ; 14 \mathrm{~h})$. Bianchini indicates that there is no need to proceed further ("non curavi amplius in hoc labore"), for the last two

16 The interpolated value for the equatio $\mathrm{c}_{4}$ is 9;52' in MSS $\mathrm{P}_{1}$ and $\mathrm{P}_{4}$, but 9;53' in MSS $\mathrm{BC}$ and Va. The correct result, 60;38', is obtained with the intermediate value 9;53'.

17 A simpler way to address this kind of computation, where the product of the sines of two quantities is the sine of a third $(\sin a=\sin b \cdot \sin c)$, was later displayed in a single table by Regiomontanus. This table, computed in 1467 , was published in Vienna in 1514 in a volume bound together with Peurbach's Tabulae eclypsium (see below). 
equated times differ by less than one minute. Accordingly, the final equated values are $88 ; 32^{\circ}$ for the zenith distance, $146 ; 8^{\circ}$ for the eastern angle, and 63;2'for the total parallax. Bianchini's procedure is essentially the same as that outlined by Ptolemy in Alm. 6.10, except that Bianchini does not take into account solar parallax.

Bianchini computes parallax in latitude in chapter 32 following the same procedure as described in chapter 29 for the longitudinal component of parallax. The result is $35 ; 5^{\prime}$, which he designates by "aspectus lune in latitudine equata". In chapter 33 , he derives the equated argument of lunar latitude at the middle of the visible eclipse. The starting point is the argument of lunar latitude at true conjunction, which is given as $5 ; 45^{\circ}$. We note that this value differs from the two found previously, $5 ; 47^{\circ}$ and $5 ; 41^{\circ}$, but agrees with that given in MS Va. Bianchini finds $358 ; 10^{\circ}$ for the argument of lunar latitude at the time of mid-eclipse, corresponding to a southern latitude of $0 ; 9^{\circ}$.

As explained in chapter 34 , with this value for the argument of lunar latitude, one enters the two tables for solar eclipses and, after interpolation, finds 8;20 digits and 9;8 digits at greatest and least distances, respectively, for the fraction of the solar diameter eclipsed. For the true lunar anomaly determined previously, 206;17 $7^{\circ}$, Bianchini computes 9;6 digits, which corresponds to an eclipsed area of the solar disk of 8;22 digits. The chapter ends with a reference to "tractatus $8^{\circ}$ capitulo" of his Flores Almagesti where he had explained this issue. ${ }^{18}$

The computations of the times and arcs associated with the duration of the eclipse are addressed in chapters 35 and 37. To compute the arc corresponding to immersion, that is, from first contact to eclipse-middle, we are told to proceed in the same way as for the fraction of the solar diameter eclipsed in the previous chapter, and to enter the two tables for solar eclipses with the argument of lunar latitude. After interpolation, Bianchini finds 31;51' for the arc that he calls minuta casus, corresponding to the time "a principio usque ad medium”. Dividing it by the superatio, $0 ; 33,37^{\circ} / \mathrm{h}$, he gets $0 ; 57 \mathrm{~h}$. Since the time previously computed for eclipse-middle was $7 ; 14 \mathrm{~h}$, the resulting times for the beginning and the end of the solar eclipse are found to be $8 ; 13 \mathrm{~h}$ and 6;17h, respectively, before noon. ${ }^{19}$ As indicated by Bianchini, sunrise

18 The reference seems incomplete. MS C1 agrees with MS P1, whereas MS P4 reads "tractatus $8^{\circ}$ " and MSS BC and Va read " $8^{\circ}$ capitulo".

19 “ $8 ; 13$ " is a scribal error for " $8 ; 11$ ". Note that $7 ; 14 \mathrm{~h}+0 ; 57 \mathrm{~h}=8 ; 11 \mathrm{~h}$. MSS C1 and Va have the correct reading, $8 ; 11 \mathrm{~h}$. 
on 18 July 1460 at Ferrara occurs at "ho.9. m.14. horologii", that is, 9;14h "on the clock". The time referred to the clock is counted from sunset, as was often the custom in Italian towns. In a paragraph in the same chapter, but not found in all manuscripts, we are told that the beginning of the eclipse occurs at 8;26h on the clock, which corresponds to $0 ; 48 \mathrm{~h}$ before sunrise. Thus, the times for the beginning, middle, and end of the eclipse are $8 ; 26 \mathrm{~h},{ }^{20}$ 9;23h, and 10;20h after sunset (local time), respectively, making a little more than half the duration of the eclipse visible after sunrise and providing the citizens of Ferrara with a superb spectacle to be observed in the future: a partially-eclipsed Sun rising above the eastern horizon.

Chapter 35 closes with a summary of the main data for the visible eclipse:

Beginning: 2;30h before true conjunction;

Middle: 1;33h before true conjunction;

End: 0;36h after true conjunction.

With the hourly velocities of the two luminaries, Bianchini derives the apparent positions at these times:

Apparent position of the Sun at the beginning, middle, and end of the eclipse: Leo $3 ; 53^{\circ}$, Leo $3 ; 55^{\circ}$, and Leo 3;57 ${ }^{\circ}$, respectively;

Apparent position of the Moon at the beginning, middle, and end of the eclipse: Leo $2 ; 29^{\circ}$, Leo $3 ; 3^{\circ}$, and Leo $3 ; 37^{\circ}$, respectively.

Chapters $36-38$ address the computation of the lunar eclipse of July $1460 .{ }^{21}$ As was the case for the solar eclipse, the initial step consists in computing true opposition of the Sun and the Moon. For this purpose, Bianchini uses the tables for the radices and mean motions for conjunction belonging to his set of planetary tables [Chabás and Goldstein 2009, 79-85, Tables 57-62]. The results for mean opposition are:

Time: 3 July 1460 at 6;44h after noon;

Mean solar longitude: $110 ; 52^{\circ}$;

Mean lunar anomaly: $18 ; 14^{\circ}$;

Mean argument of lunar anomaly: $171 ; 54^{\circ}$.

Since the value of the solar apogee for 1460 is $90 ; 48^{\circ}$ as already noted in chapter 24 , the resulting solar anomaly is $20 ; 4^{\circ}$. The corresponding true solar longitude at mean opposition is $110 ; 9^{\circ}$ and its hourly motion is $0 ; 2,23^{\circ} / \mathrm{h}$ [Chabás and Goldstein 2009, 85-87, Table 63]. Bianchini enters the table for the Moon at mean conjunction and finds the true longitude of the Moon,

$20 \mathrm{MS} \mathrm{P}_{4}$ reads erroneously 8;36h.

${ }^{21}$ Chapter 36 is missing in MS Va. 


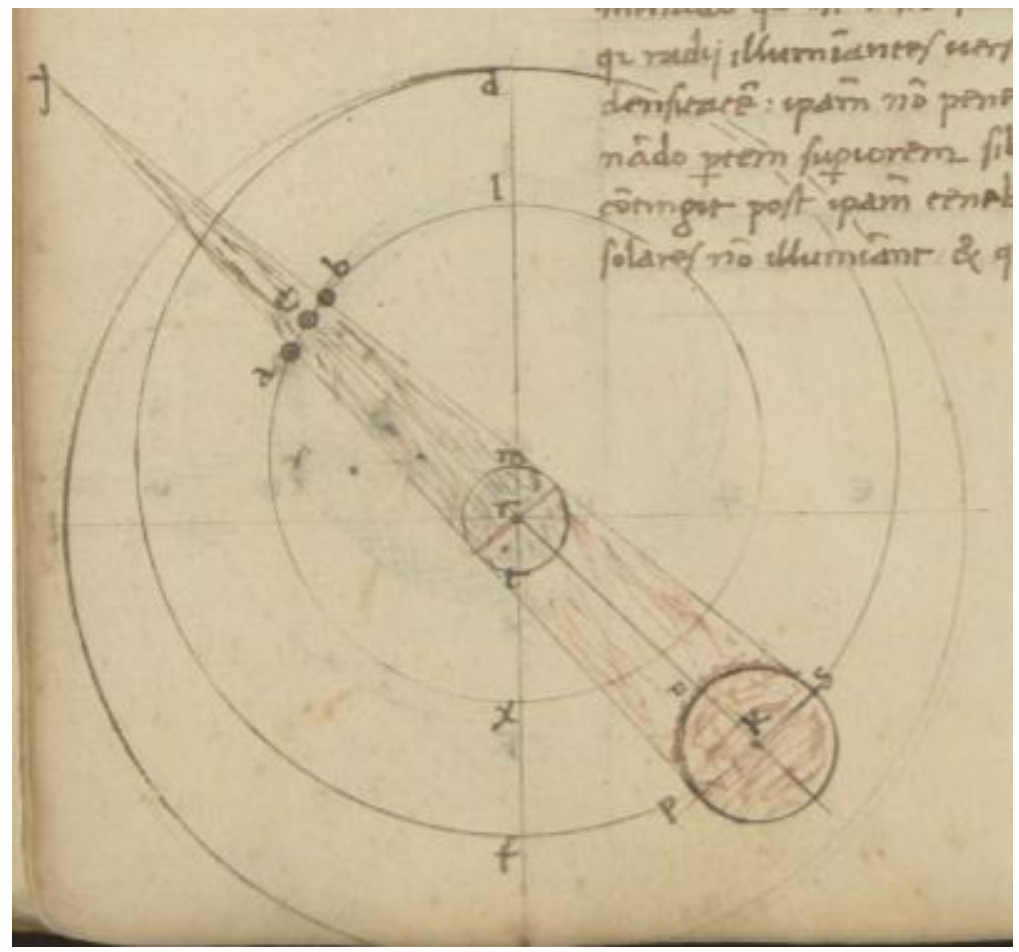

Figure 7. Lunar eclipse, MS C1, 26v

(chapter 6)

$288 ; 28^{\circ},{ }^{22}$ its hourly velocity, $0 ; 29,47^{\circ} / \mathrm{h}$, and the argument of lunar latitude at mean opposition, 210;30 [Chabás and Goldstein 2009, 87-91, Table 64]. With the hourly velocity in elongation, $0 ; 27,24^{\circ} / \mathrm{h}$, he finds the time between mean and true opposition, 1;30h, and deduces from it the time of true opposition: July 3, 8;14h, corresponding to 8;27 h after noon, local time in Ferrara, after taking into account the equation of time.

In chapter 37, Bianchini computes the times of the lunar eclipse. He first computes the argument of lunar latitude at true opposition, given as "2.51.15. id est.g.171.15". ${ }^{23}$ With this value, he enters the tables for lunar eclipses at

${ }^{22}$ MSS $\mathrm{P}_{1}, \mathrm{P}_{4}$, and $\mathrm{C}_{1}$ refer to true opposition, whereas the reference should be to mean opposition. MS BC has "vere oppositionis" where "vere" is crossed out and replaced by "medie" above it. MSS $\mathrm{P}_{1}$ and $\mathrm{P}_{4}$ give $288 ; 28^{\circ}$ for the true longitude of the Moon, whereas MSS BC and C1 have, correctly, 289;28 .

${ }^{23}$ Here is an example of both notations. 
greatest and least distances [see Table 9, p. 22 above] and finds the magnitude in digits (puncta) and the arc of immersion (minuta casus) corresponding to these two extreme positions. He notes that there is no totality. After computing the true anomaly at true opposition, 19;15 $5^{\circ}$, he interpolates in the table of parallax, yielding 4;15 digits for the magnitude of the eclipse and 33;26' for the minuta casus. The result of dividing this last value by the superatio is $1 ; 14 \mathrm{~h}$, which is then subtracted and added to the time of true opposition, $8 ; 27 \mathrm{~h}$ after noon, to obtain the times of the beginning and the end of the eclipse, 7;13 h and 9;41 h after noon, respectively, at Ferrara, on 3 July 1460. The computation of the positions of the Sun and the Moon at the beginning, middle, and end of the eclipse follows in chapter 38. First, Bianchini enumerates the values at mean opposition for the longitudes of the two luminaries, their velocities, and the time between mean and true opposition. ${ }^{24}$ Again, by means of the superatio, he finds the Sun at $\mathrm{Cnc} 20 ; 13^{\circ}$ and the Moon at Cap $20 ; 13^{\circ}$ at true opposition. At the beginning of the eclipse, the positions are $\mathrm{Cnc} 20 ; 10^{\circ}$ and Cap 19;36 $6^{\circ}$, respectively. At the end of the eclipse, they are $\mathrm{Cnc} 20 ; 16^{\circ}$ and Cap $20 ; 50^{\circ}$, respectively.

\section{Giovanni Bianchini and Georg Peurbach}

Other astronomers had computed solar and lunar eclipses and had given detailed accounts of their calculations. John of Genoa, one of the earliest Alfonsine astronomers in Paris, computed the solar eclipse of 3 March 1337, and displayed all the intermediate results in Investigatio eclipsis solis anno Christi 1337 [Miolo 2021]. Two contemporaries observed this particular eclipse: John of Murs, whose observations are recorded in El Escorial, Biblioteca del Real Monasterio, MS O-II-10, and Levi ben Gerson, who observed and computed four solar and six lunar eclipses. ${ }^{25}$

24 The values given confirm that MSS $\mathrm{P}_{1}$ and $\mathrm{P}_{4}$ referred erroneously to true, rather than mean, opposition and that they gave a faulty entry for the true longitude of the Moon.

${ }^{25}$ In the report on his observation of the solar eclipse of 1337 , John of Murs clearly distinguished visible first contact from true first contact, a distinction rarely mentioned in the Middle Ages:

Vidimus initium eclipsis Solis, Sole in altitudine 10 gradum et jam erat pars sensibilis eclipsata, quare conclusimus periferias luminarium posse contingere in altitudine 9g. [Beaujouan 1974, 30]

For Levi's observations and computations of eclipses, see Goldstein 1979. 
Most relevant to our case are the two worked examples of eclipse computation by Georg Peurbach (1423-1461), which were reproduced in his treatise Tabulae eclypsium. Peurbach's work was completed probably in 1459 and first published in Vienna in 1514 by Georg Tannstetter in a volume bound together with the Tabula primi mobilis by Regiomontanus (1436-1476). Peurbach gives detailed computations of the solar eclipse of July 1460 and the lunar eclipse of December 1460. For the solar eclipse, which is the same one that Bianchini had computed, Peurbach used his own impressive double argument table for determining the time from mean to true conjunction, which takes up 48 pages in print and provides very accurate results. He also depended on his own table for parallax, where the longitudinal component is given in hours, thus avoiding the complicated procedure used by Bianchini for finding the angle between the meridian and the ecliptic. Table 12 displays some of their results.

$\begin{array}{llr} & \begin{array}{c}\text { Bianchini } \\ \text { (Ferrara) }\end{array} & \begin{array}{r}\text { Peurbach } \\ \text { (Vienna) }\end{array} \\ \text { Mean conjunction } & \text { 18d 1;6h } & \text { 18d 1;1,57h } \\ \text { True conjunction } & \text { 17d 18;17h } & \text { 17d 18;15h } \\ \text { Beginning of eclipse } & \text { 17d 15;47h } & \text { 17d 15;54h } \\ \text { Middle of eclipse } & \text { 17d 16;46h } & \text { 17d 16;49h } \\ \text { End of eclipse } & \text { 17d 17;43h } & \text { 17d 17;44h }\end{array}$

Table 12. Comparison between the times of the eclipse of July 1460 given by Bianchini and Peurbach (All hours are counted from noon)

Bianchini indicated that the beginning of the eclipse occurs at $8 ; 26 \mathrm{~h}$ "on the clock", which corresponds to 0;48h before sunrise at Ferrara; whereas Peurbach tells us that at Vienna it occurs about 35 minutes (fere) before sunrise. The modern difference in longitude between the two cities is about $4 ; 45^{\circ}$, corresponding to about 19 minutes of an hour.

Bianchini and Peurbach computed with their own tables, the former using signs of $60^{\circ}$ and the latter signs of $30^{\circ}$, and there are differences in the various steps in the computation, notable for finding parallax. Nevertheless, their results are in very good agreement and both authors computed correctly according to the method that they described. This comes as no surprise, for both were using the same basic tool, the Parisian Alfonsine Tables, although in different versions. 


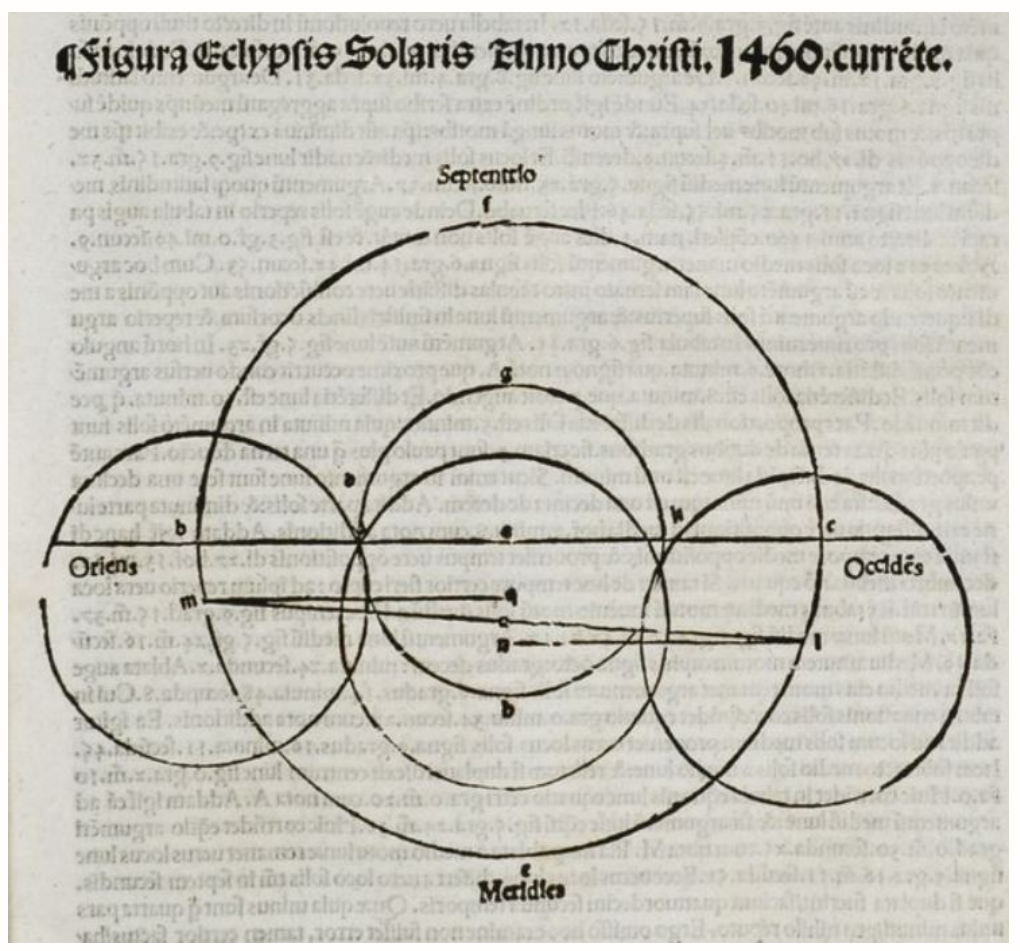

Figure 8. Peurbach's drawing of the solar eclipse of July 1460 in his Tabulae eclypsium, ch. 6

(Vienna, 1514)

In his Tabulae eclypsium, Bianchini did not include diagrams for the two specific eclipses that he computed in advance. Rather, in chapters 5 and 6 , which deal with the drawing of figures of eclipses in general, he provides diagrams to support the explanation [see Figure 6, p. 29 and Figure 7, p. 33, above]. In contrast, Peurbach's treatise includes illustrations for the two particular eclipses given as worked examples, of which only one is displayed in Figure 8.

\section{Conclusions}

A few conclusions arise from a close reading of Bianchini's Tabulae eclypsium. First is that the text of this treatise was composed after the Flores Almagesti, since a few chapters in the Tabulae eclypsium were taken from the part of the Flores Almagesti concerning eclipses. Second, the Tabulae eclypsium is a separate work consisting of text and tables that were intended 
for a readership of competent astronomers, since it offers complete and detailed worked examples of two eclipses, one solar and one lunar, to take place in 1460. This date, moreover, sets an upper limit to the period when this treatise was composed. Since the text also provides specific data of four lunar eclipses, the last of which is dated 1 May 1455, and in the Flores Almagesti year 1456 is mentioned as the "current year", it is likely that the Tabulae eclypsium was not finished before that date. This suggests that Bianchini's Tabulae eclypsium was written between 1456 and 1460.

In the two worked examples, there are many intermediate computations, the results of which are not always displayed but are always correct, indicating that the purpose was not just pedagogical. Bianchini was indeed a good and precise computer, who understood well the procedures that he was using and, in particular, those in the Almagest. Characteristic of Bianchini's work is the dominant use of signs of $60^{\circ}$, although various other notations are found. Sexagesimal numbers are often presented as digits separated by dots, as in "1.2.3", without specifying the unit of each part, meaning "one sign of $60^{\circ}, 2^{\circ}$, and $3^{\prime \prime}$, which, when combined with the standard notation, becomes "s.1.g.2.m.3". Sometimes, however, Bianchini uses decimal notation for degrees, as in $62^{\circ}$, or zodiacal signs, as in Gem $2^{\circ}$.

In the text, there are references to quite a number of tables. Some are found in Bianchini's Tabulae astronomiae, the large set of tables for the planets that he had completed in about 1442. In particular, he uses his extensive and unprecedented tables for syzygies. For the Tabulae eclypsium, Bianchini also compiled new tables, all based on tables and procedures already in the Almagest, but going beyond them in that he recomputed and extended Ptolemy's tables, while introducing a different value for the obliquity of the ecliptic and applying spherical trigonometry where Ptolemy had used plane trigonometry. In this sense, Bianchini combined innovation with strict adherence to Ptolemy's Almagest.

8.1 Acknowledgment We thank an anonymous referee for providing us with insightful comments. 


\section{APPENDIX \\ TITLES AND INCIPITS OF THE CANONS TO THE \\ TABULAE ECLYPSIUM}

Base manuscript: Paris, BnF 7270 (MS P1), 167r-181r. Copied in 1461.

In those instances where the base manuscript offers no title, we have added in italics the one given in MS Vat. lat. 2228 (MS Va), 1r-16r, copied in 1470 by Joannes Carpensis at Ferrara.

Title: Canones tabularum de eclypsibus luminarium de blan[chinis] editarum

Prohemium. In libro Florum Almagesti per Ioannem Blanchinum...

1. Primo sciendum est quod sol de per se non eclypsatur...

2. Eclypsis autem lune causatur ex interpositione...

3. Diversitatis aspectus declaratio

4. De certis erroribus in tabulis veteribus observatis

5. De figura eclypsis solis actualiter demonstranda

6. De figura eclypsis lune actualiter demonstranda

7. De imperfecta compositione tabularum observatarum pro diversitate aspectus lune invenienda

8. De erroribus Albategni in acceptione quantitatis diametri lune

9. De quantitate diametri lune secundum ptholomeum veraciter invenienda.

Dico ergo ad inveniendum diametrum lune...

10. Altitudinem lune temporibus eclypsis in qualibet hora diei invenire

11. De inventione angulorum ex meridiano \& orbe signorum equaliter correspondentium in omni regione

12. Angulos orientales in quacumque particulari regione invenire

13. De angulis orientalibus atque occidentalibus zodiaci cum circulo altitudinis in qualibet hora diei \& loco invenire

14. De diversitate aspectus lune prima que est ex distantia ipsius a zenith in quacumque regione volueris

15. De diversitate aspectus lune in longitudine \& latitudine tam ante quam post meridiem invenienda

16. De quantitate temporis et corporis solis obscuratione. Data est in precedentibus doctrina ad inveniendam diversitatis aspectus lune...

17. Et quia supra inventum est quantum ex diametro solis

18. Prout ab intuentibus videri...

19. Ptholomeus ipse prout ante dictum est demonstravit 
20. Sequitur demonstratio per experientiam.

Prima eclypsis per me ex 4 or consideratis...

21. De proportione diametri umbre ad diametrum lune in eclypsibus

22. De eclypsi lune narratio

23. Quantitatem superficiei per quantitatem diametri lune eclipsati invenies.

Habitis enim punctis diametri lune eclypsatis...

24. De eclypsi solis futura que erit 1460 de mense iulii ad situm ferrarie perscrutari

25. Altitudinem luna ab orizonte invenire

26. Angulum orientalem lune invenire

27. Angulum occidentalem invenire

28. Diversitatem aspectus primam invenire

29. Diversitatem aspectus lune in longitudine tantum invenire

30. Sequitur pro horis eclypsis visibilis $2^{\circ}$ equandis invenire

31. Sequitur pro horis eclypsis visibilis $3^{\circ}$ equandis perscrutatio

32. De diversitate aspectus lune in latitudine invenienda

33. Argumentum latitudinis lune ad medium eclypsis visibilis perscrutari

34. De quantitate diametri solis eclypsati invenire

35. De minutis casus ultimo propalandis

36. Eclypsim lune per tabulas invenire

37. De quantitate durationis \& mora lunaris eclypsis invenienda

38. Loca solis \& lune in principio, medio \& fine eclypsis perscrutari

39. Ad inveniendum diversitatem effectus [read: aspectus] lune centro epicicli distante ab auge deferentis

Explicit: cum quibus operari potes in omnibus operationibus ad propositum.

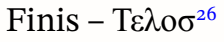

\section{BIBLIOGRAPHY}

Beaujouan. G. 1974. "Observations et calculs astronomiques de Jean de Murs (1321-1344)". Actes du XIVe Congrès international d'Histoire des Sciences (Tokyo-Kyoto) 2:27-30. Reprinted in idem, Par raison des

26 In the manuscript, the last letter is an ordinary sigma rather than a sigma in final position. 
nombres: L'art du calcul et les savoirs scientifiques médiévaux (1991), essay 7. Aldershot.

Boffito, G. 1907-1908. "Le Tavole astronomiche di Giovanni Bianchini da un codice della Collezione Olschki”. La Bibliofilia 9:378-388 and 446-460.

Chabás, J. 2016. "An Analysis of the Tabulae magistrales by Giovanni Bianchini”. Archive for History of Exact Sciences 70: 543-552.

2019. Computational Astronomy in the Middle Ages: Sets of Astronomical Tables in Latin. Madrid.

Chabás, J. and B. R. Goldstein. 2009. The Astronomical Tables of Giovanni Bianchini. Leiden/Boston.

2012. A Survey of European Astronomical Tables in the Late Middle Ages. Leiden/Boston.

Federici Vescovini, G. 1968. "Bianchini, Giovanni”. Dizionario biografico degli Italiani 10:194-196.

Garuti, P. 1992. "Giovanni Bianchini: Compositio instrumenti (Cod. Lat. 145 T.6.19) della Biblioteca Estense di Modena”. Rendiconti Classe di Lettere e Scienze Morali e Storiche 125: 95-127.

Goldstein, B. R. 1979. "Medieval Observations of Solar and Lunar Eclipses". Archives Internationales d'Histoire des Sciences 29: 101-156. 1997. "The Physical Astronomy of Levi ben Gerson”. Perspectives on Science 5: 1-30.

Magrini, S. 1917. “Joannes de Blanchinis Ferrariensis e il suo carteggio scientifico col Regiomontano (1463-1464)". Atti e memorie della deputazione ferrarese di storia patria 22.3: 1-37.

Miolo, L. 2021. John of Genoa's Opus astronomicum: Edition, English Translation and Commentary. Turnhout. Forthcoming.

Nallino, C. A. 1903-1907. Al-Battānī sive Albatenii Opus astronomicum. 2 vols. Milan.

Neugebauer, O. 1975. A History of Ancient Mathematical Astronomy. Berlin.

Peurbach, G. 1514. Tabulae eclypsium. Vienna.

Rosińska, G. 1984. Scientific Writings and Astronomical Tables in Cracow: A Census of Manuscript Sources (XIVth-XVIth Centuries). Wrocław. 1996. “The 'Fifteenth-Century Roots' of Modern Mathematics". Kwartalnik Historii Nauki i Techniki 41: 53-70. 
Rosińska, G. 1997. "The 'Italian Algebra' in Latin and How It Spread to Central Europe: Giovanni Bianchini's De Algebra (ca. 1440)”. Organon 26-27: 131-145. 1998. "The Euclidean spatium in Fifteenth-Century Mathematics". Kwartalnik Historii Nauki i Techniki 43:27-41. 2006. “'Mathematics for Astronomy' at Universities in Copernicus' Time: Modern Attitudes toward Ancient Problems”. Pp. 9-28 in M. Feingold and V. Navarro edd. Universities and Science in the Early Modern Period. Dordrecht/Boston.

Saliba, G. 1996. "Arabic Planetary Theories after the Eleventh Century AD”. Pp. 1:58-127 in R. Rashed ed. Encyclopedia of the History of Arabic Science. London/New York.

Swerdlow, N. 1973. "The Derivation and First Draft of Copernicus's Planetary Theory: A Translation of the Commentariolus with Commentary". Proceedings of the American Philosophical Society 117: 423-512. 1990. "Regiomontanus on the Critical Problems of Astronomy". Pp. 165-195 in T. H. Levere and W. R. Shea edd. Nature, Experiment, and the Sciences. Dordrecht.

Thorndike, L. 1950. "Giovanni Bianchini in Paris Manuscripts". Scripta Mathematica 16: 5-12 and 169-180. 1953. "Giovanni Bianchini in Italian Manuscripts". Scripta Mathematica 19: 5-17.

Toomer, G. J. 1984. Ptolemy's Almagest. New York.

Van Brummelen, G. 2018. "The End of an Error: Bianchini, Regiomontanus, and the Tabulation of Stellar Coordinates". Archive for the History of Exact Sciences 72: 547-563. 2021. "Before the End of an Error: Giovanni Bianchini's Original Flawed Treatise on the Conversion of Stellar Coordinates". Archive for the History of Exact Sciences 75: 109-124. 